Phonological Data and Analysis Volume 1, Article 1: 1-28 (2019)

https://doi.org/10.3765/pda.v1art1.19

Received 17 January 2018; revised 5 May 2018; accepted 28 January 2019. (C) 2019 Dustin Bowers.

Published by the Linguistic Society of America with permission of the author under a CC BY 3.0. license.

\title{
Positional vs. sonority-driven stress in Gujarati: New experimental evidence
}

\author{
Dustin Bowers ${ }^{\mathrm{a} *}$
}

aUniversity of Arizona - bowersd@email.arizona.edu

\begin{abstract}
Stress in Gujarati (Indo-Aryan, India and Pakistan) has been alternately claimed to be strictly positional or sensitive to vowel sonority. The latter analyses figure prominently in arguments for scalar markedness constraints (de Lacy 2002, 2006). This study presents acoustic measures and speaker intuitions to evaluate both the positional and sonority-driven stress hypotheses. The acoustic results support weakly cued positional stress, though speaker intuitions for primary stress placement were inconsistent. This replicates Shih's (2018) negative findings, and indicates that Gujarati stress should not figure in discussions of sonority-driven stress or associated theoretical proposals.
\end{abstract}

Keywords: Gujarati; stress; prosody; vowel sonority; scalar markedness

\section{Introduction}

The stress system of Gujarati (Indo-Aryan, India and Pakistan) is the subject of some descriptive disagreement. The most prominent current claim is that stress is driven by an intricate interaction between syllable position and vowel sonority (de Lacy 2002; 2006, on sonority-driven stress generally, see Kenstowicz 1997; Hargus 2001; Crowhurst \& Michael 2005), though no two analyses agree entirely (Firth 1957; Cardona 1965; Adenwala 1965; Mistry 1997; Cardona \& Suthar 2003; Doctor 2004; Schiering \& van der Hulst 2010; Modi 2013). In contrast, some work claims that Gujarati stress is word initial (Turner 1921; Master 1925; Pandit 1958; Patel \& Mody 1960; Shih 2018). This study reports acoustic evidence from two experiments designed to test the initial stress and sonority-driven stress analyses. Additionally, speaker intuitions on stress placement were collected in a third experiment. The results favor the initial stress analysis, though stress is phonetically weak and speakers lack strong intuitions for stress placement.

The paper will first establish the case for fixed initial stress in Gujarati. Prior claims for fixed stress are reviewed in $\S 2$. The results of an experiment seeking potential acoustic correlates of fixed initial stress are reported in $\S 3$. F0 contours were found to consistently align an initial low with the first syllable of the word, non-initial syllables are more strongly coarticulated with neighboring vowels, and the nucleus of the initial syllable may also be longer than the nucleus of the second syllable. Not only is this consistent with claims

*I would like to thank Kie Zuraw, Paul de Lacy, Jason Shaw, Tim Mills, Patricia Keating, Sun-Ah Jun, Megha Sundara, Amanda Rysling, Shu-hao Shih, and Bruce Hayes for discussion and comments on this work. For their help in obtaining the data for this study, I would like to thank Kavita Krishnakant, Ashvina Panchal, Krishnakant Panchal, and the Shree Swaminarayan Gurukul. Finally, for their help in processing the data, I would like to acknowledge Dan Keating, Irene Yoo, Grace Gaspardo, and Annie Chapman. This work was supported by the UCLA Graduate Research Mentorship Program and the Social Sciences and Humanities Research Council of Canada. All errors are my own. 
that the first syllable is regularly stressed, it is also reminiscent of analyses of other languages of the Indian subcontinent (see Khan 2008; 2014 on Bengali, Keane 2006; 2014 on Tamil).

The correct description of Gujarati stress is of interest to phonological theory because arguments for scalar markedness hierarchies have prominently featured claims that Gujarati has sonority-driven stress (de Lacy 2002; 2006). The sonority-driven analysis proposed by de Lacy $(2002 ; 2006)$ is reviewed in $\S 4$. Experiment 2 (§5) seeks acoustic measures from pairs of identical vowels that de Lacy $(2002 ; 2006)$ predicts to differ in stress value. While duration and F1/F2 correlate with de Lacy's sonority-driven analysis, a more parsimonious explanation attributes the observed effects to neighboring vowels. F0 and intensity are also correlated with de Lacy's sonority-driven analysis, but the effects are so small that it is doubtful they could cue stress. These results cannot confirm the existence of sonority-driven stress in Gujarati.

Experiment 3 ( $\S 6)$ collected speakers' intuitions about prominence. Speaker intuitions were found to be deeply inconsistent and did not align with any account in the prior literature. These negative results do not falsify de Lacy's sonority-driven analysis of Gujarati stress, let alone the theory of scalar markedness that it is supposed to support. They do however show that caution is required in adducing Gujarati as a case of sonority-driven stress, as the current evidence points towards it being regularly word initial.

\section{Prior positional stress analyses}

A significant body of work over the past century claims that the initial syllable of Gujarati words either categorically or variably receives stress. Such claims date at least to Turner (1921: 342-343), who states that stress "normally falls on the penultimate syllable" in his primarily disyllabic data set. "Importantly, Turner provides a large number of polysyllabic words where stress has been "transferred" to the initial syllable, suggesting that initial stress is the productive generalization. Shortly thereafter, Master (1925: 82-93) tentatively indicates that stress by default falls on the penultimate syllable of disyllables, the antepenultimate syllable of trisyllables and the pre-antepenultimate syllable of quadrisyllables, or in other words, on the initial syllable.

Later work is less equivocal, as Pandit (1958: 216), and Patel \& Mody (1960: 24) state that stress is word initial. More recently, Shih (2018) argues that the penultimate syllable of disyllables (that is, the initial syllable) is regularly stressed.

\subsection{Potential correlates of stress}

Intensity, duration, intonational contours and vowel peripherality have been proposed as correlates of word initial stress in Gujarati, though most claims are based on impressionistic data. Patel \& Mody (1960) state that stress differences are 'obvious and easily noticeable' ( $\mathrm{p}$ 20), and specifically claim that /i, u, a/ have peripheral allophones $[\mathrm{i}, \mathrm{u}, \Lambda]$ when stressed (pp. 9, 21, 22) and centralized allophones [I, $v$, ə] when unstressed. They further claim that stressed vowels are longer than unstressed vowels.

In contrast, Pandit (1958: 216) maintains that stress differences are subtle, but that "louder stress" may be optionally produced on initial syllables. Pandit explicitly denies that initial syllables are longer than other syllables and makes no mention of vowel allophony being conditioned by stress. ${ }^{2}$

\subsubsection{Prior instrumental results}

A recent study by Shih (2018) reports acoustic effects that may support an initial stress analysis of Gujarati. Specifically, Shih compared the realizations of $/ i, o, u, a /$ in the first and second syllables of disyllabic words on F1, F2, duration, intensity, and F0. Of these measures, Shih reports that F0 and F1 are potential correlates

\footnotetext{
${ }^{1}$ Note that Turner (1921: 342-343) goes on to state that stress may fall "on the last [syllable, DAB] if that is long and is derived from a long Sanskrit syllable". Gujarati is not currently thought to have a vocalic length contrast (Cardona \& Suthar 2003), though Turner (1921) clearly disagrees and provides several arguments for a length contrast having been at least diachronically active.

${ }^{2}$ Shih (2018) mistakenly cites Pandit's identification of word-final lengthening as stress conditioned lengthening.
} 
of initial stress. For F1, Shih found that $/ \mathrm{a} /$ is significantly lower in the first syllable than in the second syllable, and asserts without statistical corroboration that /o/ has similar allophony. For the high vowels /i, $\mathrm{u} /$, Shih only reports a significant height difference for $/ \mathrm{u} /$ in one of the two conditions he tests.

Regarding F0, Shih shows that the initial syllable is regularly associated with low F0, which proceeds to rise to a peak in the final syllable. This is potentially strong evidence for an initial stress analysis, because intonational phonology is widely thought to align high or low F0 targets to stressed syllables (Pierrehumbert 1980; Beckman \& Pierrehumbert 1986). It is not unambiguous evidence, however, because tonal targets may also be attracted to constituent boundaries. This means that an initial low tonal target could be aligned to the left word edge, to say nothing of the possibility that the final high tonal target could be aligned to a final prominent syllable or the right word edge. Given this ambiguity, F0 data alone cannot establish initial stress, though the plausibility of $\mathrm{F} 0$ as a stress correlate would increase if additional parameters also pick out the first syllable.

\subsubsection{Increased contrast in initial syllables}

One such potential phonological correlate is an increased range of contrast in stressed syllables. Initial syllables in most dialects of Gujarati license an expanded range of vocalic contrast, with $/ \varepsilon, \rho /$ occurring in addition to /i, e, a, ə, o, u/ (Firth 1957; Cardona \& Suthar 2003: 661). ${ }^{3}$ The strength of this argument for Gujarati as a whole is slightly attenuated by the existence of dialects that have no contrast between $/ \varepsilon, \rho /$ and /e, o/ (Firth 1957; Modi 1994). Though word initial syllables may license greater contrast independently of stress (Beckman 1998), similar contrast patterns in conjunction with intonational tone associations have also been adduced in support of phonetically weak word initial stress in Bengali and Tamil (see Khan 2008; 2014; Keane 2014).

In all, the prior literature indicates that if Gujarati has word initial stress, it is fairly weakly cued. The next section reports the results of an experiment that examines the acoustics of syllables drawn from trisyllabic words.

\section{Experiment 1: initial stress}

An initial stress analysis predicts that initial syllables will be augmented on some phonetic parameter relative to subsequent syllables. This experiment compares the realizations of four vowels $/ \mathrm{i}, \mathrm{u}, \mathrm{o}, \mathrm{a} / \mathrm{in}$ different positions of the word.

\subsection{Method and materials}

To control for the effects of neighboring consonants on duration and formant frequencies, each vowel was constrained to appear in the same immediate consonantal environment (see Keane 2006 for a similar design in Tamil). Furthermore, because vowels in open syllables are typically longer than vowels in closed syllables, all target syllables were closed. Table 1 shows the core set of words.

Note that Table 1 omits items for /o/ in medial syllables. The original candidate items were [əmboro] 'hair bun', and [dabori] 'lefty', which historically had [rd] sequences, but now have [r], the intervocalic allophone of /d/ in Gujarati. As a result, their medial syllables were not segmentally identical to [bor] in [bor.sə.li] 'tree species' and [ $\widehat{\left.\mathrm{t} \int \partial . n i . b o r\right] ~ ' t y p e ~ o f ~ b e r r y ', ~ a n d ~ t h e i r ~ m e d i a l ~ s y l l a b l e s ~ a r e ~ a l s o ~ n o t ~ c l o s e d . ~}$ Nonetheless, exact environmental equivalence is not necessary for all acoustic parameters, and so these items, as well as others that will feature in experiment $2(\S 5)$ were included in the results for some of the potential correlates of stress here. These additional items are shown in Table 2.

26 native speakers of Gujarati (17 male, 9 female) living in Bangalore, India participated in this study.

\footnotetext{
${ }^{3}$ Nair (1979) states that the famous Gujarati breathiness contrast in vowels is limited to word initial syllables, though breathy vowels in non-initial syllables are provided by Patel \& Mody (1960: 31).
} 
Table 1: Main stimuli for initial stress comparisons. Syllable position varies while neighboring segmental content is controlled.

\begin{tabular}{|c|c|c|c|}
\hline & Initial & Medial & Final \\
\hline \multirow[t]{2}{*}{ i } & hit.va.di & ma.hit.gar & pu.ro.hit \\
\hline & 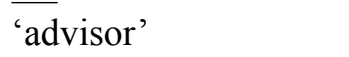 & 'informer' & 'priest' \\
\hline \multirow[t]{2}{*}{$\mathrm{u}$} & kul.pə.ti & səy.kul.ta & gu.ru.kul \\
\hline & 'high ranking official' & 'complexity' & 'religious school' \\
\hline \multirow[t]{2}{*}{$\mathrm{o}$} & bor.sə.li & - & tfə.ni.bor \\
\hline & 'tree species' & & 'type of berry' \\
\hline \multirow[t]{2}{*}{ a } & man.ha.ni & sə.man.ta & hə.nu.man \\
\hline & 'insult' & ‘similarity’ & 'name of deity' \\
\hline
\end{tabular}

Table 2: Additional stimuli for initial stress comparisons. Measurements from these items are analyzed when neighboring segments do not need to be controlled.

\begin{tabular}{|c|c|c|}
\hline & Form & Gloss \\
\hline \multirow[t]{5}{*}{$\mathrm{i}$} & nə.gi.no & ‘jewel' \\
\hline & da.gi.no & 'jewelry' \\
\hline & kə.vi.ta & 'poem' \\
\hline & hõ.fi.jar & 'clever' \\
\hline & pə.rik. $\int a$ & 'test' \\
\hline \multirow[t]{2}{*}{$\mathrm{u}$} & lim.bu.di & 'lemon tree' \\
\hline & d $\mathrm{d}_{3} \mathrm{am}$.bu.d.o & 'jambul tree' \\
\hline \multirow[t]{2}{*}{$\mathrm{O}$} & әm.bo..do & 'hair bun’ \\
\hline & da.bo.di & 'lefty' \\
\hline \multirow[t]{2}{*}{ a } & na..rəy.gi & 'orange' \\
\hline & na.rad̋.gi & 'distressed' \\
\hline
\end{tabular}

All participants had been raised in India's Gujarat province, within the dialect communities described in Cardona (1965). All but two participants reported speaking Gujarati on a daily basis. Participants were given a small monetary reward for participating. Two potential participants did not complete the study; one found the task highly stressful and the other was from a substantially different dialect community.

The words in Tables 1-2, in addition to four words used in the experiments described in $\S 5$ and $\S 6$, were each written on individual flash cards in Gujarati script. Stimuli were presented to participants one at a time. Participants were asked to say the presented word in a carrier phrase [anənde kumarne X bolva $\operatorname{kid}^{\mathrm{f}} \mathrm{u}$ ] 'Anand told Kumar to say X'. ${ }^{4}$ All items were presented to each speaker 3 times, with the deck of flash cards shuffled on each iteration through the deck. Recordings were performed with an Audio Technica head-mounted microphone and a Tascam US-144MKII external sound card. Due to experimenter error, one repetition of the word list was not recorded for one speaker.

\footnotetext{
${ }^{4}$ The embedded structure of the carrier phrase was intended to reduce the chance of a major phrase break interfering with lexical intonational events.
} 


\subsection{Segmentation criteria and measurement procedure}

The nucleus of each target syllable was segmented beginning with the onset of voicing, or if the preceding consonant was voiced, the onset of F2 was used. After voiced stops, vowels were segmented beginning immediately after the release burst. The endpoint of the vowel was taken to be the end of voiced high frequency components.

Measurements were performed in Praat with the aid of scripts. Formant measures were taken at the midpoint of the vowel. Extreme measures produced by the default parameters in Praat were re-measured by hand.

\subsection{Results}

A key lacuna in the literature on Gujarati is whether the initial low F0 value observed in Shih's (2018) disyllabic stimuli reflects a tonal target aligned to the penultimate syllable or the initial syllable/left word edge. In the present trisyllabic stimuli, this ambiguity is removed, and the initial low is observed to generally coincide with the first syllable/left word edge, though the initial low may be delayed if the word begins with a voicless consonant (see $\S 3.3 .1$ ).

It is also important to seek further confirmation of Shih's (2018) other findings. Recall that Shih found that / $\mathrm{a} /$ and perhaps $/ \mathrm{o}, \mathrm{u} /$ take more extreme F1 values when they occur in the initial syllable, while vowel duration and intensity are not significantly affected by syllable position. As shown in §3.3.2, initial and non-initial tokens of the same vowel may differ in F1 and F2, though the data do not confirm Shih's proposal that F1/F2 space is expanded for initial vowels. Rather, the effect of stress is to make the initial vowel more resistant to coarticulation.

Furthermore, $\S 3.3 .3$ shows that vowels in the second syllable of a word are shorter than their counterparts in the first syllable. Note that further corroboration on this point is desirable, since the data here is not comprehensive. Finally, §3.3.4 shows that vowels in the initial syllable have slightly less intensity than vowels in non-initial syllables, though the difference is likely imperceptible.

Statistical analysis was conducted using linear mixed effects models that were fitted using the lme4 package (Bates et al. 2015) in R ( $\mathrm{R}$ core team 2018). All models included random effects for participant, but because there could be only one item for each vocalic contrast in a position, a random effect for item was not included. Linear mixed effects models are commonly compared using the Akaike Information Criterion (AIC), though when one model is nested within another (as in traditional null-hypothesis testing), it is also appropriate to report $p$-values calculated by the likelihood ratio test (via the anova() function in R). In some cases non-nested models are compared, in that case only the change in the Akaike Information Criterion $(\triangle \mathrm{AIC})$ is reported, where positive numbers larger than 2 indicate that the proposed model provides a substantial improvement in fit (see Burnham \& Anderson 2002; Arnold 2010).

\subsubsection{FO}

If stress is regularly initial, an extreme value (either high or low) in the F0 contour could be expected to align with the initial syllable. There is a clear effect of syllable position on F0, as F0 rises in each successive syllable for the vast majority of the data. Because neighboring consonants do not need to be as strictly controlled when examining F0 data, this section analyzes measurements from all the items in Tables 1-2. The general rising pattern is shown in Figure 1, which plots extrapolated F0 curves between F0 minima in syllables with identical nuclei. Minimum F0 values are plotted because the primary concern is whether the lowest point of the rise is aligned with the initial syllable/left word boundary. Put simply, if the lowest portion of a speaker's F0 range aligns with an initial syllable, it is possible to claim that a low tonal target is aligned to an initial stress.

Figure 1 shows that speakers tend to be in the low portion of their F0 range as the word begins, and end 


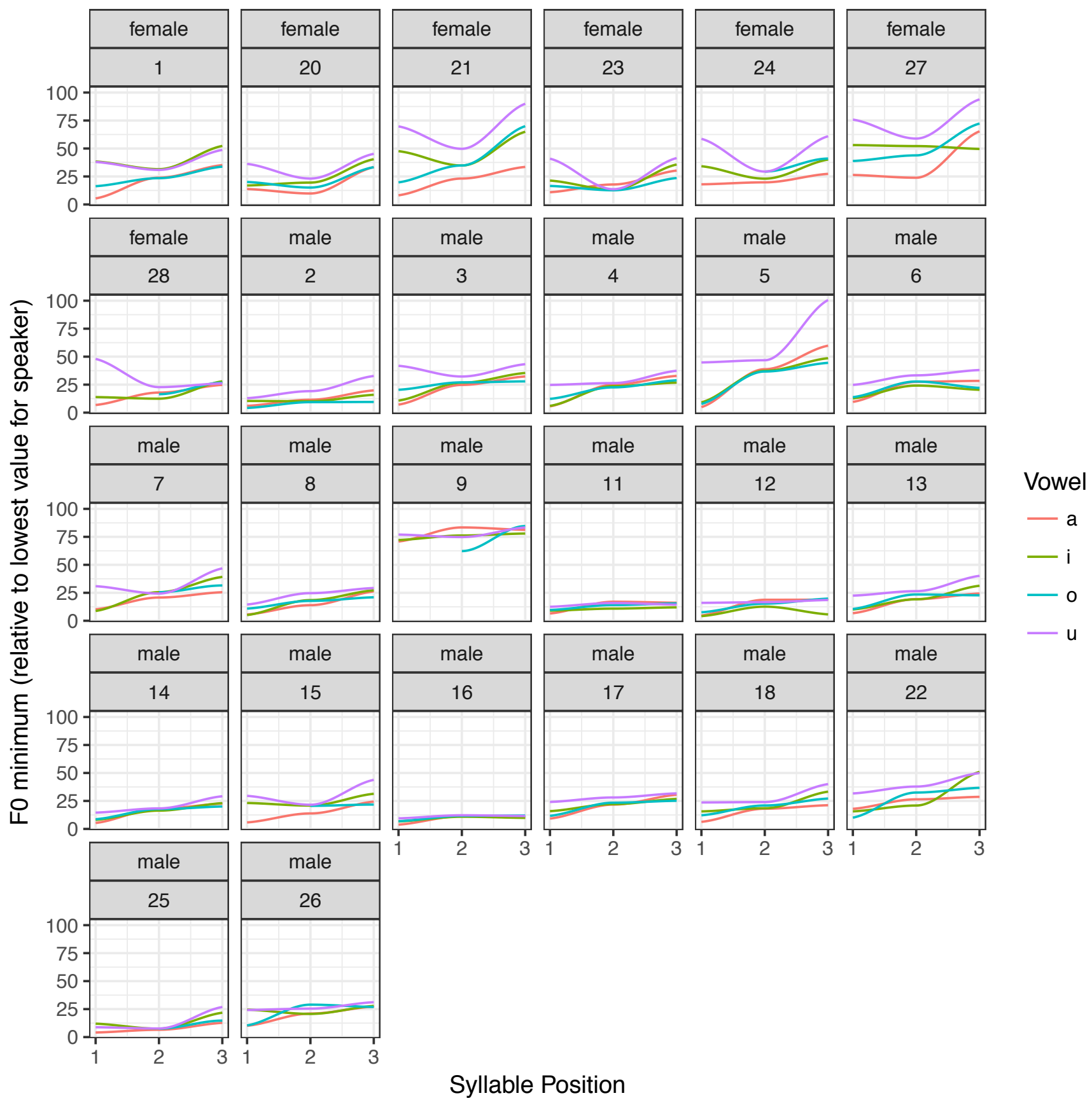

Figure 1: Relative $\mathrm{F} 0$ minima in $\mathrm{Hz}$ for /a, o, i, u/ in successive syllables by speaker. For each speaker, F0 values are relative to the lowest F0 measure recorded for the speaker. Individual data points have been suppressed to improve readability. 


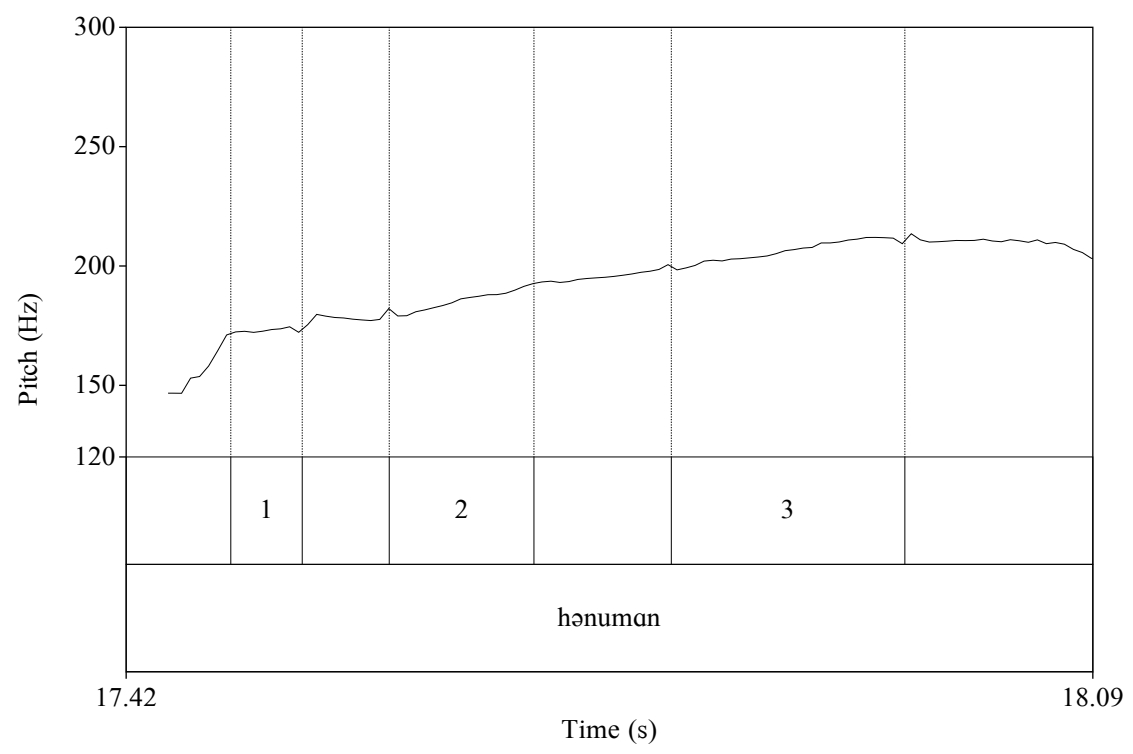

Figure 2: Pitch track for [hənuman] 'deity name' for speaker 27 (second run). Intervals spanning successive syllabic nuclei are marked with corresponding integers.

the word in the high portion of their range. This is confirmed by inspection of actual F0 traces, as seen in Figure 2.

While Figure 1 predominately shows rising contours, the extrapolated curves suggest that for female speakers and at least some of the male speakers, the lower part of their F0 range may be reached in the second syllable. Manual inspection of actual F0 contours indicates that this is not an illusion. The lowest point of the F0 contour is not strictly aligned to the first syllable. Figure 3 illustrates this for a token where the lowest stable portion of the F0 trace occurs during the onset of the second syllable in [sə.man.ta] 'similarity'.

The lowest F0 point in the contour can even be aligned with the nucleus of the second syllable as well, as shown in Figure 4.

Importantly, whether the F0 valley occurs after the nucleus of the initial syllable nearly exclusively depends on whether the first segment in the word is [-voice, +consonantal] (voiceless consonants excluding $/ \mathrm{h} /$ ). ${ }^{5}$ In light of this dependency, a simple analysis is that Gujarati intonation allows a low tonal target to be optionally displaced from its default initial position when the word begins with a voiceless consonant.

This model of Gujarati intonation is supported by statistical analysis. Table 3 shows the fixed effects for a linear mixed effects model predicting minimum F0 values in individual syllables. To reflect the fact that F0 contours consist of trajectories from the most recent reference point, syllable position was backwards difference coded, so that the fitted value for the second syllable is expressed relative to the fitted value for the first syllable (labeled $\sigma_{1} \rightarrow \sigma_{2}$ ) and the value for the third syllable is expressed relative to the second syllable (labeled $\sigma_{2} \rightarrow \sigma_{3}$ ). The model contains a random intercept for speaker, and fixed effects for gender, syllable position, vowel quality, and whether the word begins with a voiceless consonant. It also includes a two way interaction between gender and the third syllable position (to reflect the expectation that females have more dramatic pitch changes), and a three way interaction between gender, the second syllable position and whether the word initial segment is a voiceless consonant (to capture the expectation that females are

\footnotetext{
${ }^{5}$ There is one potential counter-example in these data, as on one occasion speaker 9 produced [dabodi] 'lefty' with creaky voice on the second syllable.
} 


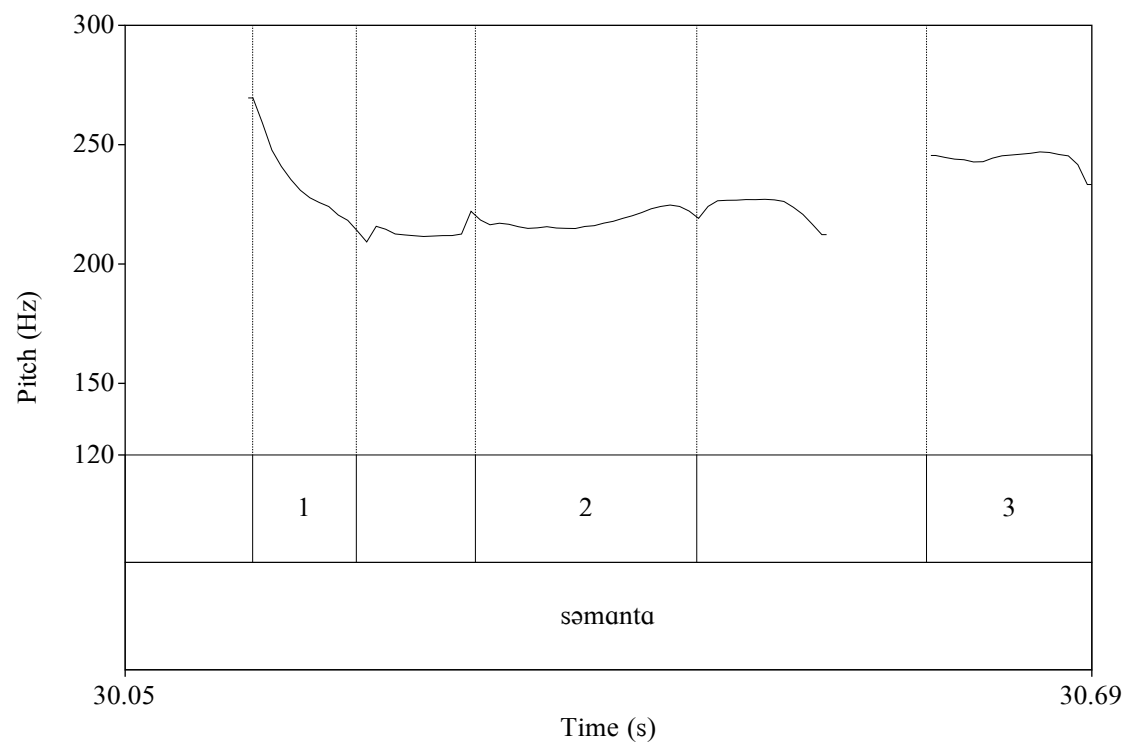

Figure 3: Pitch track for first repetition of [səmanta] 'similarity' for speaker 20. Intervals spanning successive syllabic nuclei are marked with corresponding integers.

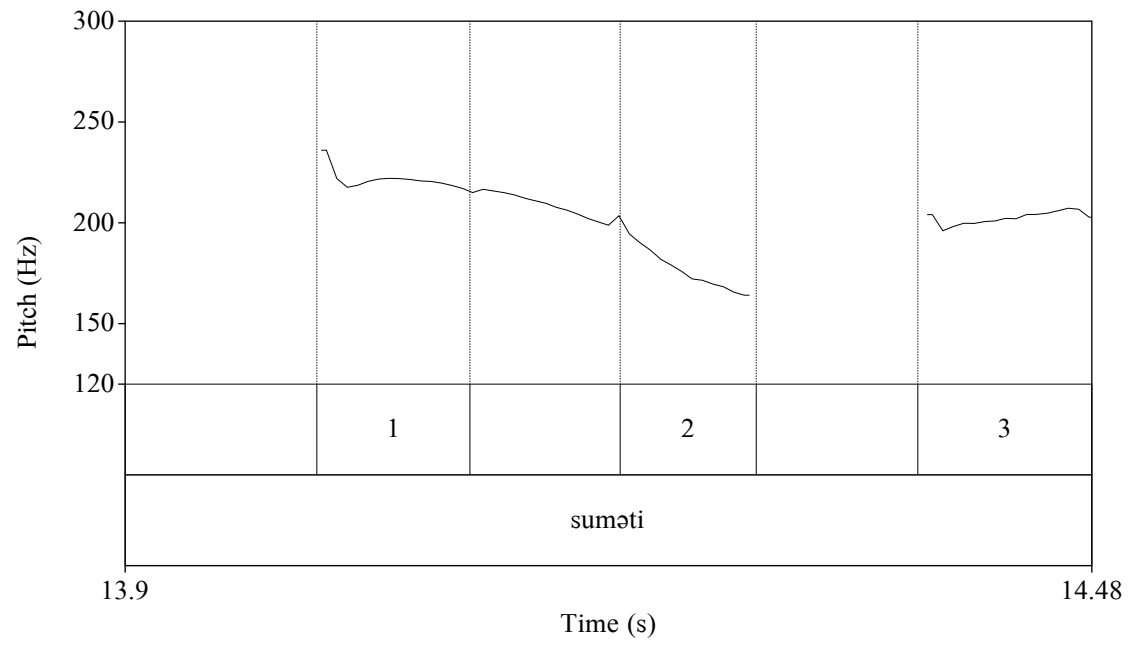

Figure 4: Pitch track for second repetition of [suməti] 'wisdom' for speaker 24. Intervals spanning successive syllabic nuclei are marked with corresponding integers. 
likely to have low F0 on the second syllable of words that begin with voiceless consonants). ${ }^{6}$

Table 3: Fixed effects of model predicting minimum F0 in initial stress experiment.

\begin{tabular}{lrrr} 
& Estimate & Std. Error & $\mathrm{t}$ value \\
\hline (Intercept) & 130.8869 & 4.0285 & 32.49 \\
female & 57.3426 & 7.7642 & 7.39 \\
$\sigma_{1} \rightarrow \sigma_{2}$ & 9.5179 & 0.8727 & 10.91 \\
$\sigma_{2} \rightarrow \sigma_{3}$ & 8.2179 & 0.8220 & 10.00 \\
$\#[+$ cons, -voi] & 2.4533 & 0.7242 & 3.39 \\
F1 (centered, rescaled) & -2.0829 & 0.3160 & -6.59 \\
$\sigma_{1} \rightarrow \sigma_{2}: \#[+$ cons, -voi] & -12.5472 & 1.7535 & -7.16 \\
female:\#[+cons, -voi] & 7.2402 & 1.3893 & 5.21 \\
female: $\sigma_{1} \rightarrow \sigma_{2}$ & -3.7152 & 1.5418 & -2.41 \\
female: $\sigma_{2} \rightarrow \sigma_{3}$ & 11.0529 & 1.5651 & 7.06 \\
female: $\sigma_{1} \rightarrow \sigma_{2}: \#[+$ cons, -voi] & -18.0670 & 3.3454 & -5.40
\end{tabular}

The model mirrors the impressions developed above. Each successive syllable has a higher F0 value than the previous syllable, with a 7.6 and $7.8 \mathrm{~Hz}$ rise for the second and third syllables for male speakers, and an additional $10.6 \mathrm{~Hz}$ rise for the third syllable for female speakers. The $2.3 \mathrm{~Hz}$ drop for female speakers in the second syllable is not a reliable effect $(|t|<2)$. The major deviation from the overall rising pattern appears when the word begins with a voiceless consonant. In that case, male speakers show a $4.2 \mathrm{~Hz}$ drop relative to the usual value for the second syllable, while female speakers show an additional $18 \mathrm{~Hz}$ drop. Note that the drop for female speakers is so pronounced that the F0 of the second syllable is estimated to be lower than that of the first syllable. This confirms the conclusion that the initial low tone target may be repelled by an initial voiceless consonant, even to the point of aligning with the second syllable for female speakers.

This model fits the data significantly better than a model that omits the effects of word initial voiceless consonants $(p<0.001, \Delta \mathrm{AIC}=88.4311)$. It also provides a better fit than a model that omits the effects of word initial voiceless consonants and syllable position $(p<0.001, \Delta \mathrm{AIC}=503.6232)$.

In sum, F0 measurements support an analysis where a low F0 turning point is aligned by default to the beginning of the word. As stated above, these F0 data in isolation cannot conclusively determine that there is word initial stress in the language, since the default tonal alignment could be to the left word boundary instead of to the initial syllable. Nonetheless, these data may weigh in favor of an initial stress analysis if further corroborating evidence can be produced.

\subsubsection{Increased coarticulation}

If initial syllables are stressed, the stress may be cued by either more peripheral realizations for initial syllables, or somewhat less directly by greater resistance to coarticulation in initial syllables. Shih (2018) reports that in initial syllables /a/, and potentially /o, u/, have more extreme F1 values than in non-initial syllables. To check this claim, F1 and F2 measures from the 'core' positional item set in Table 1 were used, plus measurements from [əmboro] 'hair bun' and [dabori] 'lefty' to fill the medial syllable gap for $/ \mathrm{O} /$ in the core item set. In the current data, /a, i/ are more peripheral in initial syllables than non-initial syllables, while the rounded vowels /o, $\mathrm{u} /$ are much less clearly affected. This is shown in Figure 5.

\footnotetext{
${ }^{6}$ It is important to limit the effect of initial voiceless segments to [+consonantal] segments, as the model in Table 3 fits more poorly when all voiceless segments are included ( $\triangle \mathrm{AIC}=-38.98)$.
} 


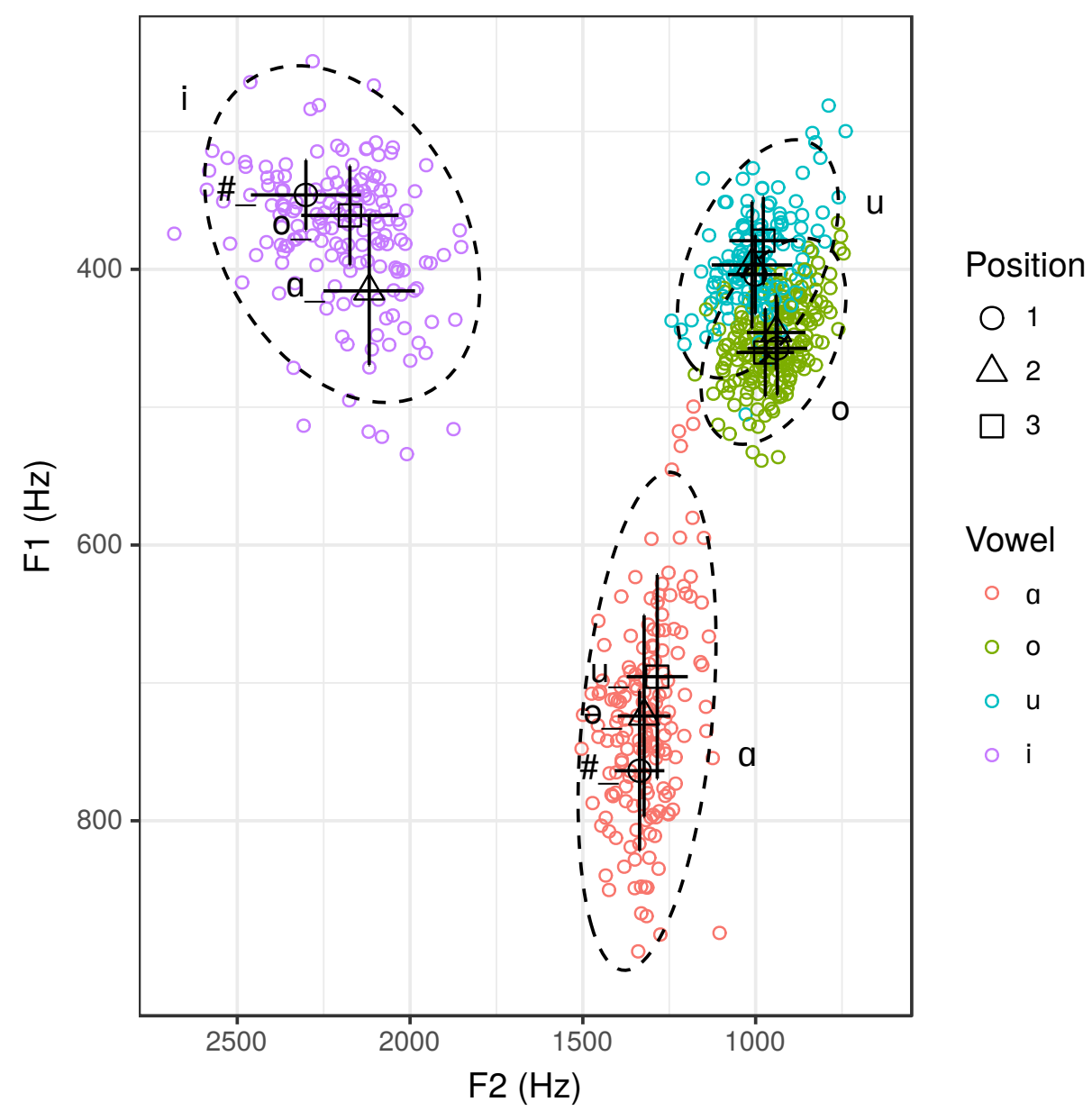

Figure 5: Vowel F1 and F2 values by syllable position for male speakers. Ellipses mark one standard deviation for entire vowel category. Error bars mark one standard deviation for each positional variant within a vowel category. Positional variants are labeled with quality of vowel in preceding syllable. Preceding vowel quality is not shown for rounded vowels, as the different variants are too close together to be legible. 
In light of his findings, Shih (2018) proposes that Gujarati has a smaller F1 space for unstressed vowels than for stressed vowels. It is not immediately clear that the present data conform to this centralization analysis, since, as is clear from Figure 5, the entire space for all non-initial vowels is not substantially smaller. Rather, if the vowel space has shrunk, the effect is clearest for unrounded vowels. Furthermore, within the unrounded vowels, final and medial vowels are not targeting the same location in F1/F2 space. The observed situation here is that the location of the non-initial vowel is heavily determined by the quality of the preceding vowel. That is, tokens of /a/ are moderately raised and backed when following /ə/ in [səmanta] 'similarity', and more severely raised and backed when following $/ \mathrm{u} /$ in [hənuman] 'name of deity'. Similarly, tokens of /i/ are more aggressively lowered following /a/ in [mahitgar] 'informer' than in [purohit] 'priest'. This is not to say that rounded vowels are completely immune to coarticulation, see §5.2.1.

These effects are statistically significant. As before, linear mixed effects models predicting F1 and F2 with a random intercept for speaker were fitted to the data. Visual inspection revealed that male and female participants treat medial and final tokens of some vowels differently, the model included a threeway interaction between gender, vowel and syllable position. The model of F1 significantly improves fit relative to a null model that includes only two-way interactions between (1) gender and vowel category and (2) syllable position and vowel category $(p<0.001, \Delta \mathrm{AIC}=98.3801)$. Similarly, the model of F2 with a three-way interaction between gender, vowel and syllable position significantly improves fit relative to the corresponding null model $(p=0.014, \Delta \mathrm{AIC}=73.37642)$.

Ultimately, the gender-specific differences in the placement of vowels in F1-F2 space is not the chief concern. To summarize the key positional effects, Table 4 provides the fixed effects of a model predicting F1 for data from male participants. A separate model was trained on data from female participants, and the effect structure is fully commensurate with the model for male speakers, modulo having less separation between $/ \mathrm{u} /$ and $/ \mathrm{o} /$ and in estimating nearly the same value for final and medial $/ \mathrm{i} /$. To facilitate comparison of effects between subsequent syllables, syllable position has been backwards difference coded.

Table 4: Fixed effects of model predicting F1 in initial stress experiment.

\begin{tabular}{lrrr} 
& Estimate & Std. Error & $\mathrm{t}$ value \\
\hline (Intercept) & 727.108 & 5.903 & 123.18 \\
$\mathrm{li} /$ & -352.992 & 4.409 & -80.06 \\
$\mathrm{/o} /$ & -273.701 & 4.325 & -63.28 \\
$\mathrm{lu} /$ & -336.048 & 4.811 & -69.85 \\
$\sigma_{1} \rightarrow \sigma_{2}$ & -40.952 & 7.661 & -5.35 \\
$\sigma_{2} \rightarrow \sigma_{3}$ & -27.281 & 7.661 & -3.56 \\
$\mathrm{li} /: \sigma_{1} \rightarrow \sigma_{2}$ & 109.955 & 10.858 & 10.13 \\
$/ \mathrm{o} /: \sigma_{1} \rightarrow \sigma_{2}$ & 31.571 & 10.573 & 2.99 \\
$/ \mathrm{u} /: \sigma_{1} \rightarrow \sigma_{2}$ & 28.905 & 12.297 & 2.35 \\
$\mathrm{i} /: \sigma_{2} \rightarrow \sigma_{3}$ & -27.390 & 10.782 & -2.54 \\
$/ \mathrm{o} /: \sigma_{2} \rightarrow \sigma_{3}$ & 41.990 & 10.112 & 4.15 \\
$/ \mathrm{u} /: \sigma_{2} \rightarrow \sigma_{3}$ & 15.265 & 12.277 & 1.24
\end{tabular}

In Table 4, the estimated initial F1 value for /a/ from [manhani] 'insult' is estimated to be 727.108 $\mathrm{Hz}( \pm 5.903)$, the medial F1 value from [səmanta] 'similarity' is $686.156 \mathrm{~Hz}( \pm 13.564)$, and the final F1 value from [hənuman] 'name of a diety' is $659.156 \mathrm{~Hz}( \pm 21.225)$. The vowel /i/ has similarly separated realizations, with an estimated initial F1 of $374.116 \mathrm{~Hz}( \pm 10.312)$, medial F1 of $443.119 \mathrm{~Hz}( \pm 28.831)$ and a final F1 of $388.448 \mathrm{~Hz}( \pm 47.274)$.

In contrast, the rounded vowels do not have substantially distinct realizations in different positions. For 
instance, summing the values of the relevant effects and standard errors shows that initial $/ \mathrm{o} / \mathrm{has}$ an estimated F1 of $453.407 \mathrm{~Hz}( \pm 10.228 \mathrm{~Hz})$, while medial/o/ has an estimated F1 of $444.026 \mathrm{~Hz}( \pm 20.801 \mathrm{~Hz})$ and final /o/ has an estimated F1 of 458.735 ( \pm 30.913$)$, which are clearly overlapping. See $\$ 5.2 .1$ for demonstration that rounded vowels do in fact undergo coarticulation in the data, even if not to the extent shown here for unrounded vowels.

Similarly, Table 5 shows the fixed effects of a linear mixed effects model predicting male F2 values. Importantly, though the effects are less robust than for F1, the final value of /a/ and the medial value of /i/ depart substantially from their respective initial syllable values. The effects for the rounded vowels show that their realizations vary little between positions.

Table 5: Fixed effects of model predicting F2 in initial stress experiment.

\begin{tabular}{lrrr} 
& Estimate & Std. Error & t value \\
\hline (Intercept) & 1313.5485 & 14.1068 & 93.11 \\
$/ \mathrm{i} /$ & 883.3912 & 9.8660 & 89.54 \\
$/ \mathrm{o} /$ & -362.7672 & 9.6781 & -37.48 \\
$/ \mathrm{u} /$ & -316.0975 & 10.7661 & -29.36 \\
$\sigma_{1} \rightarrow \sigma_{2}$ & -12.7817 & 17.1425 & -0.75 \\
$\sigma_{2} \rightarrow \sigma_{3}$ & -38.3078 & 17.1425 & -2.23 \\
$/ \mathrm{i} /: \sigma_{1} \rightarrow \sigma_{2}$ & -169.0045 & 24.2970 & -6.96 \\
$/ \mathrm{o} /: \sigma_{1} \rightarrow \sigma_{2}$ & 14.6616 & 23.6601 & 0.62 \\
$/ \mathrm{u} /: \sigma_{1} \rightarrow \sigma_{2}$ & 28.1559 & 27.5204 & 1.02 \\
$/ \mathrm{i} /: \sigma_{2} \rightarrow \sigma_{3}$ & 93.4169 & 24.1273 & 3.87 \\
$/ \mathrm{o} /: \sigma_{2} \rightarrow \sigma_{3}$ & 67.9163 & 22.6266 & 3.00 \\
$/ \mathrm{u} /: \sigma_{2} \rightarrow \sigma_{3}$ & -0.3445 & 27.4740 & -0.01
\end{tabular}

While this study does not provide clear evidence for general centralization as proposed by Shih (2018), the asymmetric coarticulation between initial and non-initial syllables is well explained by positing initial stress. Stressed segments are widely posited to have stronger representations in order to explain their greater resistance to coarticulation (Fowler 1981; Magen 1997; Yun 2007; Recasens 2015, though see Cho 2004). Positing initial stress in Gujarati allows the relative absence of coarticulation in initial syllables to be explained, while also accounting for the observed coarticulation elsewhere.

It may not be immediately obvious that initial syllables undergo less coarticulation than non-initial syllables. However, the initial syllable in the data is always preceded by /e/, due to the carrier sentence used in this study, [anənde kumarne X bolva kid ${ }^{\mathrm{h}} \mathrm{u}$ ] 'Anand asked Kumar to say X'. Because pauses during the carrier sentence were rare, coarticulation is expected in the initial syllable of target words. Nonetheless, the initial syllables do not show a strong effect of a preceding /e/. This is especially clear when considering the observed effects for /a/, where initial /a/ is lower than medial /a/, even though the former is preceded by /e/, and the latter is preceded by /ə/. Crucially, as will be shown in $\$ 5.2 .1, / \mathrm{e} /$ has higher F1 than /ə/. If word initial syllables were not somewhat immune from coarticulation, initial /a/ would be expected to be higher than medial $/ \mathrm{a} /$. That this does not happen is a point in favor of initial immunity.

There are clearly alternative explanations of this effect that do not invoke stress, most notably, initial fortition (Fougeron \& Keating 1997; Cho \& Keating 2001; 2009; Keating et al. 2003). See Shih (2018) for an argument against an initial strengthening account. As a final remark, note that invoking both initial strengthening and left word-boundary alignment of intonational targets misses a more parsimonious generalization that the initial syllable is stressed. 


\subsubsection{Duration}

If initial syllables are stressed, they may be expected to have greater duration than non-initial syllables. In the current data, a vowel in an initial syllable may be longer than the same vowel in a medial syllable. Specifically, within the items in Table 1, that is, the 'core' set of items where target vowels are controlled to occur in closed syllables, /a/ and /i/ in medial syllables are shorter than their counterparts in initial syllables. The full distribution for this data set is shown in Figure 6.

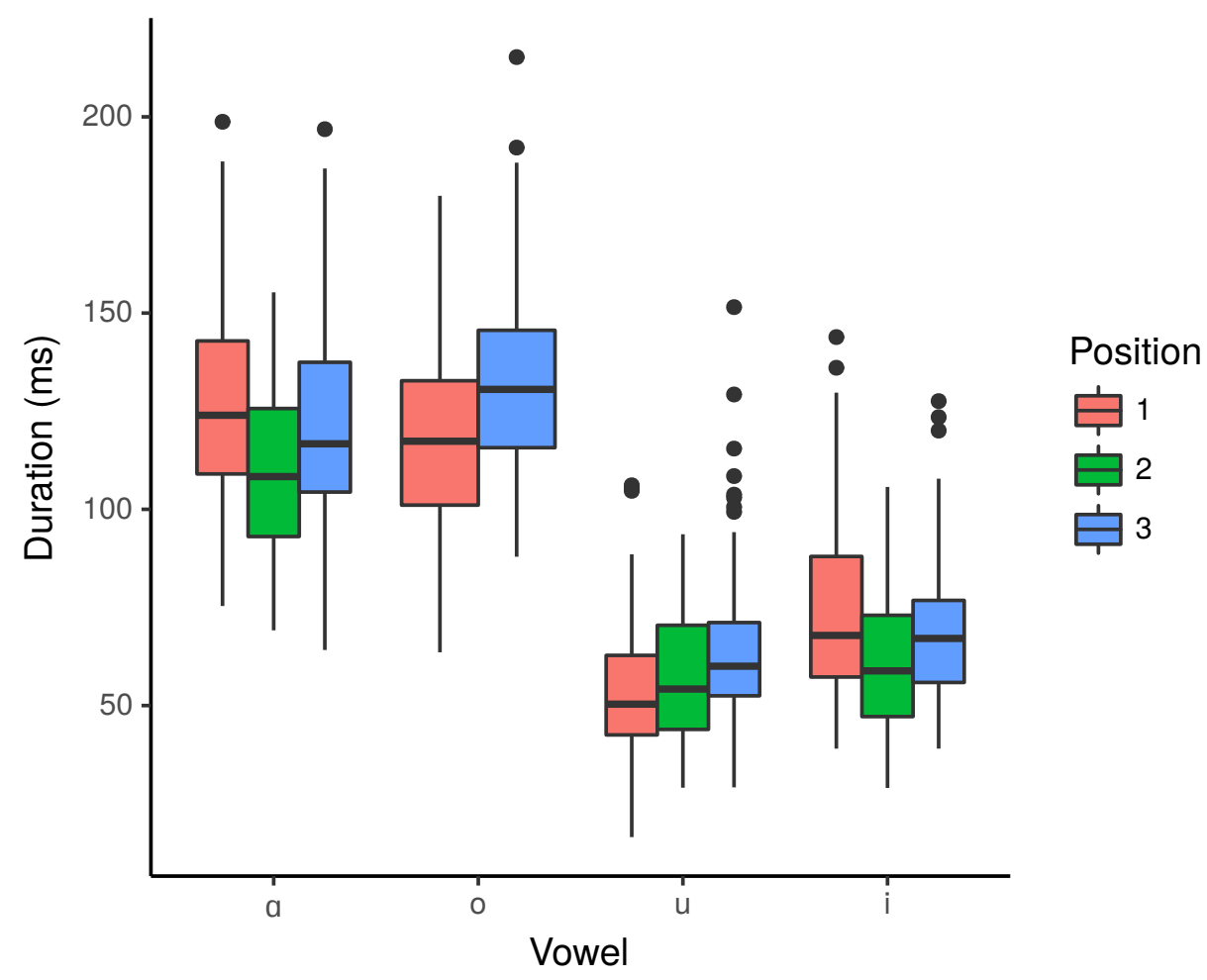

Figure 6: Duration by vowel category and syllable position. No values for medial /o/ (second group from left) are shown as no closed medial syllables had /o/ in the data set.

A conclusive statement for all Gujarati vowels cannot be made with these data, however, since the data do not include medial /o/ in a closed syllable. More importantly, medial $/ \mathrm{u} /$ also does not conform to the expected pattern. This may be due to the fact that medial / $\mathrm{u} /$ occurs in [səykulta] 'complexity', a comparatively less common word that participants were prone to pronounce carefully.

The trends in Figure 6 are confirmed by statistical analysis. In a linear mixed effects model of these data (fixed effects shown in Table 6), medial vowels are estimated to be 20 milliseconds shorter than initial vowels. This effect is quite reliable $(t=-7.20)$ and translates to a roughly $16 \%$ decrease in duration for medial /a, i/ relative to their values in initial syllables. To capture the divergent role of syllable position in each vowel category, the model includes interaction terms for vowel by position, though these are not accorded any theoretical significance. This model significantly improves fit relative to a model that omits the interaction terms $(p<0.001, \Delta \mathrm{AIC}=613.4774)$, as well as a model that additionally omits factors for syllable position $(p<0.001, \Delta \mathrm{AIC}=715.6006)$.

Further inspection of Table 6 highlights an additional tendency for /o, $\mathrm{u} /$ to be lengthened in final syllables relative to initial syllables. This is somewhat surprising, since all vowels are reportedly lengthened in final syllables in Gujarati (Pandit 1958; Desai 1992). Note that final /a, i/ are lengthened relative to their 
Table 6: Fixed effects of model predicting duration in initial stress experiment.

\begin{tabular}{lrrr} 
& Estimate & Std. Error & $\mathrm{t}$ value \\
\hline (Intercept) & 125.105 & 3.353 & 37.31 \\
female & 15.323 & 5.292 & 2.90 \\
$/ \mathrm{i} /$ & -53.905 & 2.920 & -18.46 \\
$\mathrm{/o} /$ & -11.490 & 3.131 & -3.67 \\
$/ \mathrm{u} /$ & -73.892 & 2.899 & -25.49 \\
medial & -20.869 & 2.898 & -7.20 \\
final & -7.768 & 2.868 & -2.71 \\
/i/:medial & 6.099 & 4.120 & 1.48 \\
/u/:medial & 21.951 & 4.732 & 4.64 \\
/i/:final & 1.150 & 4.093 & 0.28 \\
/o/:final & 21.941 & 4.246 & 5.17 \\
/u/:final & 17.666 & 4.078 & 4.33
\end{tabular}

medial counterparts, which raises the possibility that the prior impressionistic reports of final lengthening reflect length relative to a variable prior position in the word.

Summing up, medial vowels may be shorter than initial vowels, and final vowels may be longer than preceding vowels, though gaps in the data prevent strong conclusions. The potential asymmetry between initial vowels and medial vowels is a further potential correlate of initial stress in Gujarati.

\subsubsection{Intensity}

If word initial syllables are stressed, they may be expected to have greater intensity than non-initial syllables. Intensity was reported to not be generally correlated with syllable position by Shih (2018), though some vowels were found to have significant effects smaller than $1 \mathrm{~dB}$, which is smaller than the likely just noticeable difference for intensity (Flanagan 1955; Florentine et al. 1987). The results replicate this finding, as syllable position has significant, though small effects on intensity.

The small effects of syllable position on intensity can be seen in a linear mixed effects model predicting intensity by syllable position. Because intensity is known to be affected by gender and vowel height, as well as F0 (Hirano et al. 1969; Titze 1988; 2000), the model contained terms for F1, mean F0, and gender. This model provides significantly better fit than a null model that omits syllable position $(p<0.001$, $\Delta \mathrm{AIC}=13.7439)$. The fixed effects of the model are shown in Table 7.

Table 7: Fixed effects of model predicting intensity in initial stress experiment.

\begin{tabular}{lrrr} 
& Estimate & Std. Error & $\mathrm{t}$ value \\
\hline (Intercept) & $4.687 \mathrm{e}+01$ & $2.477 \mathrm{e}+00$ & 18.922 \\
male & $5.501 \mathrm{e}+00$ & $2.294 \mathrm{e}+00$ & 2.398 \\
F1 $(\mathrm{Hz})$ & $3.891 \mathrm{e}-03$ & $5.102 \mathrm{e}-04$ & 7.627 \\
F0 $(\mathrm{Hz}$, mean $)$ & $6.573 \mathrm{e}-02$ & $7.403 \mathrm{e}-03$ & 8.879 \\
medial & $8.995 \mathrm{e}-01$ & $2.064 \mathrm{e}-01$ & 4.359 \\
final & $2.860 \mathrm{e}-01$ & $2.318 \mathrm{e}-01$ & 1.234
\end{tabular}

As seen in Table 7, vowels in medial syllables have significantly greater intensity than vowels in initial 
syllables $(t=4.359)$. The interpretation of this effect is not straightforward, as it is not in the direction predicted by the initial stress analysis, but it also is too small to be ecologically valid. A complete explanation of this phenomenon must await further study. Note, however, that if prominence in Gujarati is realized by integrating intensity over the duration of the vowel/syllable (Lieberman 1960; Beckman 1986; Moore 1995), the increase in intensity for non-final syllables could compensate for the potential decrease in duration observed in $\$ 3.3 .3$, making syllables in all positions roughly equally prominent.

\subsection{Local summary}

The data gathered from vowels in different positions within the word suggests that initial syllables are more prominent than non-initial syllables. F0 contours target the initial syllable by default, initial syllables resist coarticulation, and initial syllables potentially have greater duration than non-initial syllables. Taken in isolation, any one of these effects can be explained without invoking stress, but taken together, this cluster of properties comports well with an initial stress analysis. The next section will evaluate the evidence for sonority-driven stress in Gujarati.

\section{Sonority-driven stress}

Though experiment 1 provides evidence in favor of word initial stress in Gujarati, the fact that the cues are fairly small and potentially explainable by other means suggests that alternative theories of stress must be considered. The prime alternative theory is that Gujarati stress is driven by vowel sonority, a proposal with a long history (Cardona 1965; Adenwala 1965; Mistry 1997; de Lacy 2002; 2006; Cardona \& Suthar 2003; Doctor 2004; Schiering \& van der Hulst 2010; Modi 2013), though no two proposals agree on all points, and some proposals are somewhat terse. This section reports the results of an experiment that tests the analysis proposed by de Lacy $(2002 ; 2006)$, the most prominent of these proposals. See Shih (2018) for an overview of the alternative sonority-driven analyses.

\subsection{The analysis}

According to de Lacy (2002; 2006, see also Cardona 1965, whose analysis is a close variant of de Lacy's), vowel sonority is the main determiner of stress, following the hierarchy $/ \mathrm{a} / \succ / \varepsilon, \rho, \mathrm{e}, \mathrm{o}, \mathrm{i}, \mathrm{u} / \succ / \partial /$. That is, main stress in trisyllabic words preferentially falls on the low vowel /a/ over mid and high vowels $/ \varepsilon, \rho, e$, $\mathrm{o}, \mathrm{i}, \mathrm{u} / \mathrm{which}$ are in turn stressed over $/ \mathrm{\partial} / .^{7}$ In the event that multiple syllables could receive primary stress under the above hierarchy, de Lacy proposes that penultimate syllables are privileged over initial syllables, which are in turn privileged over final syllables.

Additionally, according to de Lacy $(2002 ; 2006)$, the successive levels of the sonority hierarchy may only bear stress if they appear in progressively smaller sections of the syllable position hierarchy. Hence, the most privileged vowel / $\mathrm{a} /$ may be stressed in the penultimate syllable, initial syllable or in the ultima. The non-schwa class of vowels $/ \varepsilon, \rho, e, o, i, u /$ may only be stressed in the penultimate or initial syllables. Finally, /ə/ may only be stressed in the penultimate syllable. The resulting stress pattern is exemplified in Table 8, which is drawn primarily from de Lacy (2006: 233-234): ${ }^{8}$

\subsection{Reported stress correlates in sonority-driven analyses}

De Lacy $(2002 ; 2006)$ gives an impressionistic account of cues to stress that largely coincides with that given by Cardona (1965). Specifically, de Lacy (2002: 71), states that the high vowels are peripheral [i, u]

\footnotetext{
${ }^{7}$ To avoid morphological confounds, de Lacy $(2002 ; 2006)$ limits the analysis to words of up to three syllables. Cardona (1965) also limits his analysis to trisyllables.

${ }^{8}$ Some of de Lacy's transcriptions reflect distinctions only made orthographically in the modern language, or introduce contrasts that are traditionally viewed as allophonic (see especially Cardona 1965: 28), examples have been changed accordingly.
} 
Table 8: Examples of stress according to de Lacy's (2002; 2006) algorithm.

\begin{tabular}{|c|c|c|c|c|}
\hline Vowel & Penultimate & Initial & Final & Glosses \\
\hline a & 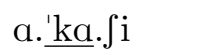 & 'pa.kis.tan & pə.rik.' $\int a$ & 'sky, Pakistan, exam' \\
\hline o & e.'ko.ter & ko.jəl.di & $-\quad-$ & '71, cuckoo' \\
\hline $\mathrm{e}$ & mo.'de.t $\mathrm{t}_{\mathrm{i}}$ & 'ke..Јәv.ni & - & 'late, education' \\
\hline $\mathrm{u}$ & kə.'官u.tor & 'ku.drə.ti & - & 'pigeon, natural' \\
\hline $\mathrm{i}$ & hõ.'的.lũ & vis.mə.rən & - & 'eager, forgetfulness' \\
\hline ә & гə.'. & - & - & 'toy' \\
\hline
\end{tabular}

in stressed open syllables (as in ['d $\left.\mathrm{f}^{\mathrm{i}} \mathrm{i} . \mathrm{mo}\right]$ 'slow' and ['d $\left.\mathrm{d}_{3} \mathrm{u} . \mathrm{l} \Lambda \mathrm{m}\right]$ 'tyranny'), while they are centralized to $[\mathrm{I}, \mathrm{v}]$ in unstressed open syllables (as in [nI. 'fa.I] 'school' and [v.'ta.vn.I] 'hurry'). ${ }^{9}$ Later, de Lacy (2006: 236) adds that $/ \partial /$ is backed to $[\Lambda]$ in open stressed syllables, as in ['d $\widehat{d}_{3} \Lambda$.min] 'land', which contrasts with unstressed [ə] in [pə.'t $\Lambda$ yg] 'kite'.

De Lacy (2002: 71) and Cardona (1965) further state that stressed syllables are the loci for intonational contours. The empirical data presented in $\$ 3.3 .1$ contradicts this claim, as the default declarative intonational contour features a rise across the word that is clearly not perturbed by stress as described by de Lacy. However, de Lacy (2002: 71) raises a separate possibility, namely, that stress is correlated with raised F0, possibly only for female speakers (de Lacy 2006: 235). ${ }^{10}$ Again, if de Lacy is describing a high tone pitch accent, that is clearly not present in the data presented above. However, it is possible that the rising pitch contour deviates slightly from its normal trajectory during the stressed syllable, so §5.2.3 will report F0 measures.

Finally, de Lacy (2006: 235) states that stress is correlated with increased intensity and duration, though Cardona (1965: 21) states that duration is not a correlate of stress. The allophony of $/ \mathrm{i}, \mathrm{u}, \mathrm{\partial} / \mathrm{and}$ the purported behavior of intonational contours are the only reported phonological correlates of stress. There are no reported additional stress-dependent patterns of allomorphy or affixation.

\section{Experiment 2: sonority-driven stress}

\subsection{Methods and materials}

The participants and design of this experiment were identical to experiment 1 , with the only difference occurring in the set of analyzed stimuli. This experiment compared the stressed and unstressed realizations for six vowels /a, ə, e, o, i, u/. The target vowel in each stressed-unstressed pair occurred in the same position in the word (penultimate syllable for non-/a/ vowels, initial syllable for /a/), and the neighboring segments of the target vowel were identical within pairs. ${ }^{11}$ Table 9 provides the words used, with the target syllable underlined.

Each target word was written in Gujarati orthography and presented in random order amongst the items used in experiment 1. Again, due to experimenter error, one repetition of the wordlist for one speaker was

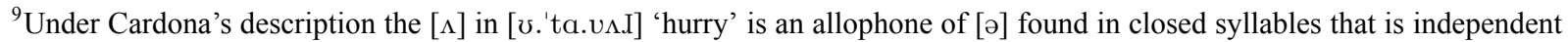
of stress.

${ }^{10}$ At face value, de Lacy (2002: 71) is positing both raised F0 on stressed syllables and intonational pitch contours targeting stressed syllables. It is unclear how this would be observed. The portion of the contour that aligned to the stressed syllable would be raised, but since it was always aligned to the stressed syllable, it is not clear what benchmark it would be raised against.

${ }^{11}$ The positional asymmetry between non-/a/ vowels and /a/ was necessitated by de Lacy's $(2002 ; 2006)$ stress algorithm. Penultimate /a/ must be stressed under the algorithm, so a stress contrast can only be obtained in non-penultimate position. Similarly, /ə/ can only be stressed if it is in the penultimate syllable, so a stress contrast can only be obtained in penultimate position. With at least one vowel guaranteed to be the odd category out, the decision to make that vowel be /a/ was taken at random.
} 
Table 9: Stimuli for sonority-driven stress experiment.

\begin{tabular}{|c|c|c|c|}
\hline Vowel & Stressed & Unstressed & Glosses \\
\hline a & 'na.rəy.gi & 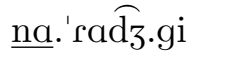 & 'orange, distressed' \\
\hline $\mathrm{O}$ & әm.'bo.do & 'da.bo.di & 'hair bun, lefty' \\
\hline e & tə.'be.lo & 'sam.be.lo & 'horse stable, rod' \\
\hline $\mathrm{u}$ & lim.'bu.di & ' $\mathrm{d}_{3} \mathrm{am} . \mathrm{bu} . \mathrm{d}$.o & 'lemon tree, jambul tree' \\
\hline i & nə.'i.no & 'da.gi.no & 'jewel, jewelry' \\
\hline ә & səm.'mə.ti & 'su. $\underline{\text { mə.ti }} . t$ & 'consensus, wisdom' \\
\hline
\end{tabular}

not recorded. Additionally, the /e/ pair was not recorded for one speaker.

\subsection{Results}

Linear mixed effects models were fitted for individual acoustic parameters to determine whether the inclusion of stress improved model fit. The tested acoustic parameters were intensity, duration, F0 (minimum, maximum, mean, range), F1, and F2.

\subsubsection{F1 and F2}

If the sonority-driven stress analysis is correct, the stress may be cued by either more peripheral realizations for stressed syllables, or somewhat less directly by greater resistance to coarticulation in stressed syllables. Figure 7 illustrates the vowel space for male speakers. The expected allophony of $/ \mathrm{i}, \mathrm{u}, \mathrm{\partial} /$ is not observed, as only the stressed and unstressed tokens of /a/ show appreciable separation. However, the unstressed and stressed tokens of /ə/ differ primarily in F1, not in F2, as would be expected if stressed/ə/ were backed. More generally, the target syllables appear to be drawn towards neighboring vowels, with the largest effects seen in /ə/ being attracted towards /u/ in [suməti] 'wisdom' and /o/ being attracted towards /i/ in [dabodi] 'lefty'.

As in experiment 1, the F1 and F2 data are analyzed in separate linear mixed effects models. The models include terms to account for the effects of phonological vowel category and gender of the speaker. Because the expected direction of the effect of stress differs by vowel, the stress models for F1 and F2 include an interaction between stress and vowel category. Table 10 shows the fixed effects for predicting F1. The model with stress as a predictor fits the data significantly better than the null model that omits stress $(p<0.001$, $\triangle \mathrm{AIC}=89.622$ )

Only $\mathrm{F} 1$ of $/ \mathrm{a} /(t=-4.78)$ and $/ \mathrm{o} /(t=2.26)$ is reliably predicted by sonority-driven stress in this model. Once the baseline $3 \mathrm{~Hz}$ increase for unstressed/vowels $(t=0.35)$ is accounted for, the estimated effects for $/ \mathrm{a} /$ and $/ \mathrm{o} /$ are respective drops of $56.5 \mathrm{~Hz}$ and $25.2 \mathrm{~Hz}$ when unstressed. This corresponds to a modest raising of the vowel. Similar results obtain for F2, as shown in Table 11. The model of F2 with effects for stress fits significantly better than the null model without such effects $(p<0.001, \Delta \mathrm{AIC}=/ 47.76)$.

In the model, only the $\mathrm{F} 2$ of $/ \mathrm{\partial} /$ is reliably predicted by stress $(t=-2.47)$. The estimated effect for $/ \partial /$, after accounting for the baseline $7.7 \mathrm{~Hz}$ increase for unstressed vowels $(t=0.38)$, is a drop of $64.2 \mathrm{~Hz}$ when unstressed, corresponding to a backing gesture.

Skepticism is warranted for the claim that the observed effects are due to stress. Most saliently, the two vowels with the most pronounced effects /o, ə/, are the non-front mid vowels, which are not a commonly encountered natural class. A more natural explanation hinges on the fact that the raised variants of $/ \mathrm{o}, \mathrm{\partial} / \mathrm{are}$ the only non-high vowels that are adjacent to high vowels when their counterparts are not (e.g. [dabodi] 'lefty' vs. [əmbodo] 'hair bun' and [suməti] 'wisdom' vs [səmməti] 'consensus'). It should come as no surprise that /o, $\mathrm{\partial} /$ have the most aggressive shifts in F1, because high vowels are known to be the most 


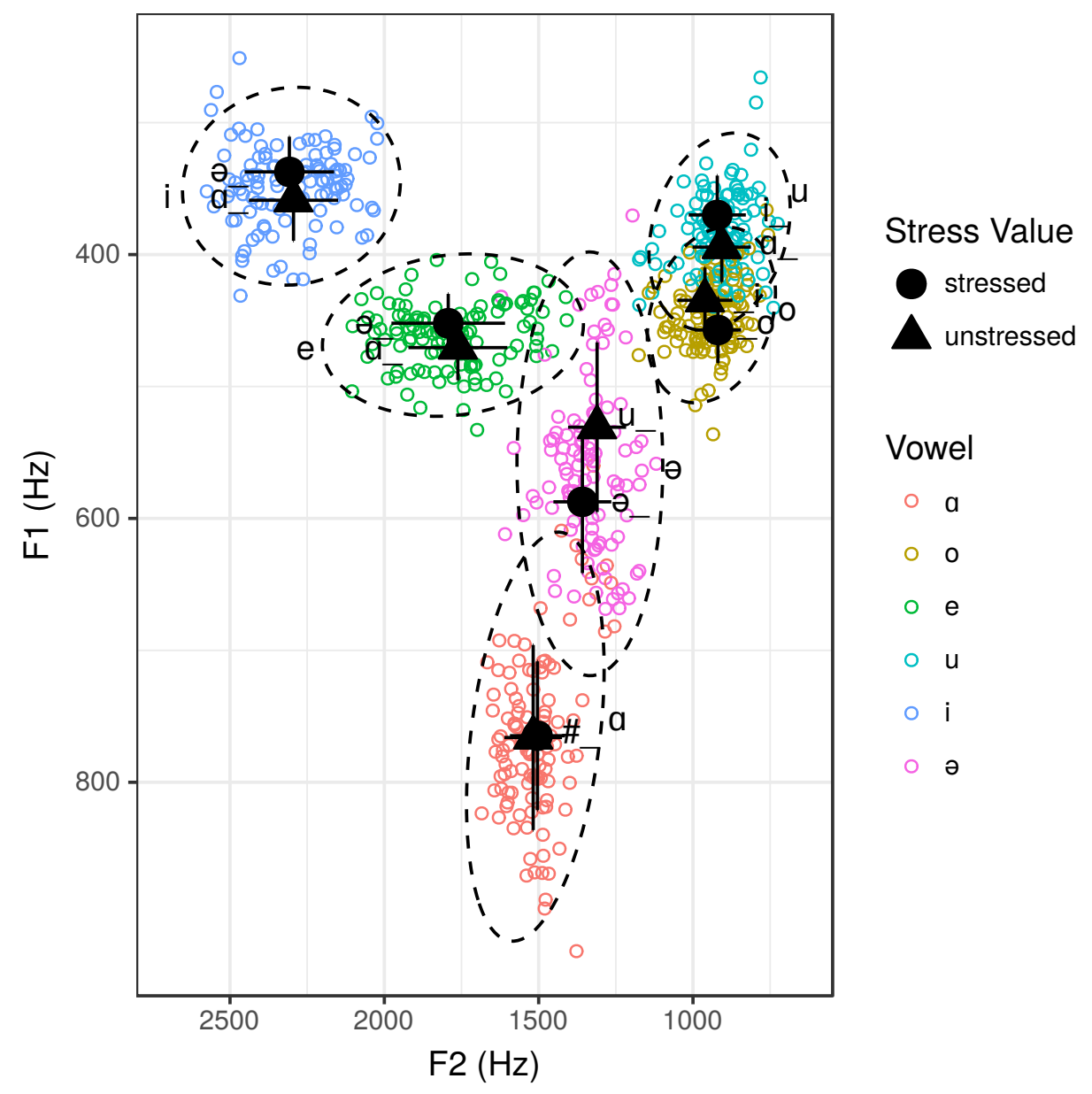

Figure 7: F1 by F2 plot for vowels produced by male speakers. Ellipses mark one standard deviation for entire vowel category. Error bars mark one standard deviation for stressed/unstressed category within each vowel. Vowel categories are labeled with quality of vowel in preceding or following syllable. 
Table 10: Fixed effects of model predicting F1 in sonority-driven stress experiment.

\begin{tabular}{lrrr} 
& Estimate & Std. Err & $\mathrm{t}$ value \\
\hline (Intercept) & 850.39 & 13.606 & 62.5 \\
/// & -196.864 & 8.842 & -22.27 \\
/e/ & -354.888 & 8.806 & -41.44 \\
/i/ & -479.862 & 8.770 & -54.72 \\
/o/ & -359.846 & 8.838 & -40.71 \\
/u/ & -437.892 & 8.832 & -49.58 \\
male & -48.898 & 14.354 & -3.41 \\
unstressed & 3.030 & 8.710 & 0.35 \\
/ə/:unstressed & -59.546 & 12.455 & -4.78 \\
/e/:unstressed & 15.820 & 12.516 & 1.26 \\
/i/:unstressed & 19.149 & 12.381 & 1.55 \\
/o/:unstressed & -28.182 & 12.444 & -2.26 \\
/u/:unstressed & 17.800 & 12.486 & 1.44
\end{tabular}

aggressive triggers of coarticulation in jaw height (Recasens 2012). Similarly, it is not surprising that /o/ has the most aggressive shift in $\mathrm{F} 2$, since / $\mathrm{i}$ / is the most aggressive trigger for lingual coarticulation (Recasens \& Espinosa 2009). The remaining pairs of target syllables in the study are adjacent to less aggressive vowels, and so have smaller effects, albeit still in the same direction.

Furthermore, the sonority-driven stress explanation for these stimuli is not transferrable to the results from experiment 1 . In experiment 1 , the realizations of especially / $\mathrm{a}, \mathrm{i} /$ varied according to the quality of neighboring vowels as well. Importantly, under the sonority-driven stress algorithm, the stressed vowels of [sə.'man.ta] 'similarity' and [hə.nu.'man] 'name of deity' should pattern with the stressed vowel of ['na.fəy.gi] 'orange'. Comparison of Figures 5 and 7 shows that these ostensibly stressed instances of /a/ do not form a natural class to the exclusion of the putatively unstressed tokens. Similarly, [hit.'va.di] 'advisor', 'ma.hit.gar 'informer' and [pu.'ro.hit] all should contain unstressed /i/, but Figures 5 and 7 show that putatively stressed /i/ in [nə.'gi.no] 'jewelry' falls well within the putatively unstressed range. On the other hand, the coarticulation explanation is consistent between both sets of data.

In short, under the sonority-driven analysis of stress, stress is a property that is determined by nearby vowels. What is annotated in Figure 7 and Tables $10-11$ as a stress contrast is equivalent to a categorization based on the vowels in adjacent syllables. Ultimately, coarticulation to these neighboring vowels is sufficient to account for the asymmetries observed. These results are not enough to corroborate de Lacy's account of sonority-driven stress. It may still be possible that stressed vowels undergo less coarticulation than unstressed vowels, as was proposed in experiment 1 , but that would require a much larger study featuring putatively stressed and unstressed vowels in a variety of environments.

\subsubsection{Duration}

If stress follows the sonority-driven stress analysis, stressed syllables may be expected to have greater duration than unstressed syllables. Duration for $/ \mathrm{i}, \mathrm{e}, \mathrm{o}, \mathrm{u} /$ breaks modestly along the lines predicted for sonority-driven stress, as can be seen in Figure 8. However, there is little difference between stressed and unstressed /a, $\partial /$.

Including the interaction between stress and vowel category as a predictor results in a significant improvement in fit relative to a stressless model $(p<0.001, \Delta \mathrm{AIC}=59.568)$. Both the stress model and the null model include a term to account for the effect of vowel height, though because it is common for /ə/ to 
Table 11: Fixed effects of model predicting F2 in sonority-driven stress experiment.

\begin{tabular}{lrrr} 
& Estimate & Std. Err & t value \\
\hline (Intercept) & 1754.130 & 29.161 & 60.15 \\
/ə/ & -127.967 & 20.658 & -6.19 \\
/e/ & 319.349 & 20.575 & 15.52 \\
/i/ & 835.713 & 20.490 & 40.79 \\
/o/ & -643.559 & 20.650 & -31.16 \\
/u/ & -648.721 & 20.635 & -31.44 \\
male & -243.148 & 30.090 & -8.08 \\
unstressed & 7.653 & 20.352 & 0.38 \\
/ə/:unstressed & -71.867 & 29.100 & -2.47 \\
/e/:unstressed & -23.245 & 29.243 & -0.79 \\
/i/:unstressed & -21.540 & 29.928 & -0.74 \\
/o/:unstressed & 13.940 & 29.076 & 0.48 \\
/u/:unstressed & -8.705 & 28.940 & -0.30
\end{tabular}

be shorter than vowels of the same height, phonological vowel categories are used rather than F1. The fixed effects of the model appear in Table 12.

Table 12: Fixed effects of model predicting duration in sonority-driven stress experiment.

\begin{tabular}{lrrr} 
& Estimate & Std. Err & $\mathrm{t}$ value \\
\hline (Intercept) & 135.498 & 3.514 & 38.56 \\
/ə/ & -75.256 & 2.680 & -28.08 \\
/e/ & -41.891 & 2.669 & -15.69 \\
/i/ & -39.925 & 2.658 & -15.02 \\
/o/ & -10.192 & 2.679 & -3.80 \\
/u/ & -30.534 & 2.677 & -11.41 \\
unstressed & 2.834 & 2.640 & 1.07 \\
/ə/:unstressed & -3.314 & 3.775 & -0.88 \\
/e/:unstressed & -9.876 & 3.794 & -2.60 \\
/i/:unstressed & -13.950 & 3.753 & -3.72 \\
/o/:unstressed & -14.036 & 3.772 & -3.72 \\
/u/:unstressed & -9.972 & 3.754 & -2.66
\end{tabular}

The middle tier of the sonority scale (/e, o, i, u/) is consistently shortened in the unstressed condition, with $/ \mathrm{o} /(t=-3.72)$ and $/ \mathrm{i} /(t=-3.72)$ showing stronger effects than $/ \mathrm{e} /(t=-2.6) \mathrm{or} / \mathrm{u} /(t=-2.66)$. After accounting for the baseline $2.8 \mathrm{~ms}(t=1.07)$ increase in duration for unstressed vowels, /e, o, i, u/ are shortened between $11.2 \mathrm{~ms}(/ \mathrm{o} /, \pm 6.412 \mathrm{~ms})$ and $7 \mathrm{~ms}(/ \mathrm{u} /, \pm 6.394 \mathrm{~ms})$. Relative to the duration of the stressed vowel category, the largest percentage drop is $11.6 \%(/ \mathrm{i} /)$, and the smallest percentage drop is $6.8 \%$ $(/ \mathrm{u} /)$.

Note that stress scarcely affects $/ \mathrm{a} /$, as it is estimated to be lengthened by $2.8 \mathrm{~ms}$ when unstressed, though this effect is likely not reliable, as the $t$ value is 1.07. Under the view that Gujarati indeed has sonority-driven stress, it is surprising that the vowel that most robustly attracts stress would not be augmented. Under a theory 


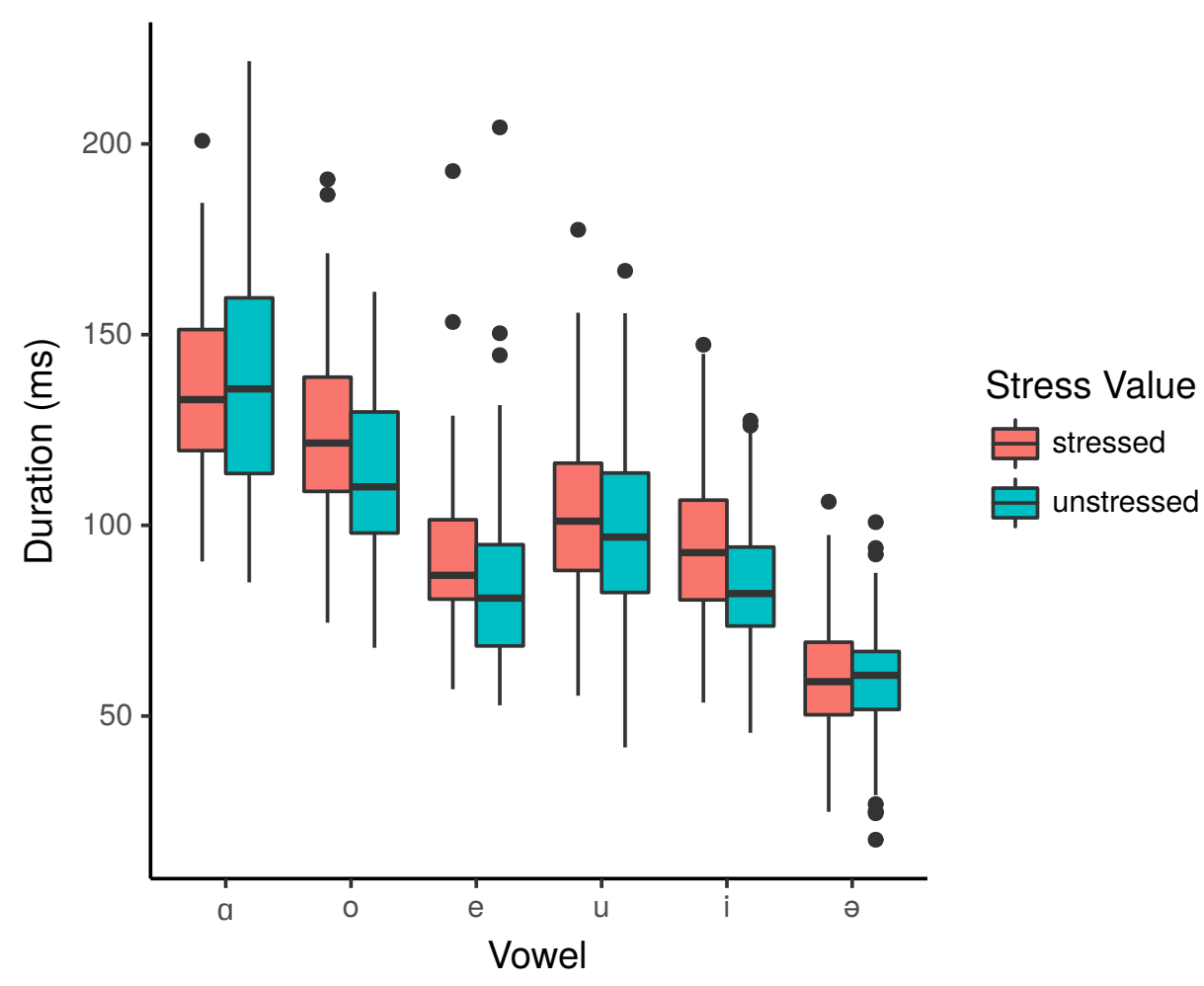

Figure 8: Plot of duration by stress (under the sonority analysis) for individual vowel qualities.

that posits stress, it is also unexpected for the direction of the effect to differ between vowels.

A more convincing analysis of the duration data refers not to stress, but to the disproportionate length of the segment /a/ (see Figure 8). Recall that the putatively unstressed, shortened vowels /e, o, i, u/ are all preceded by / $\mathrm{a} /$ in the data, as seen in ['sambelo] 'rod' or ['dagino] 'jewelry'. Some of the duration allotted to /a/ may come at the expense of neighboring segments.

Under this explanation, the ostensibly unstressed vowels are being reduced due to their proximity to $/ \mathrm{a} /$, not because they are unstressed. One prediction of this is that the vowels that are closer to /a/ will see greater reduction in duration than those that are further away. This prediction is borne out in the data, as /e, $\mathrm{u} /$ are separated from / $\mathrm{a} /$ by two segments in ['sambelo] 'rod' and ['dzambudo] 'jambul tree', and have the smallest reduction in duration.In contrast, $/ \mathrm{i}, \mathrm{o} /$ are separated from / $\mathrm{a} / \mathrm{by}$ only one segment in ['dagino] 'jewelry' and ['dabodi] 'lefty', and are more reduced in duration. Tellingly, Table 12 shows that /a, ə/, which are not preceded by $/ \mathrm{a} /$ in the data, show very little distinction in duration between the stressed and unstressed conditions.

Importantly, a linear mixed effects model that instantiates this alternative analysis produces a better fit to the duration data. The model includes fixed effects for vowel category and whether the vowel was preceded by /a/ divided by the number of intervening segments, but omits stress according to de Lacy's model. Relative to the stress model illustrated in Table 12, this model substantially improves fit $\left(\mathrm{AIC}_{\text {stress }^{-}}\right.$ $\left.\mathrm{AIC}_{\mathrm{a}-\text { distance }}=9.24\right)$. The fixed effects of the model are shown in Table 13.

Under this model, a post-/a/ vowel is expected to be shortened by roughly $8.6 \mathrm{~ms}( \pm 1.444 \mathrm{~ms})$ when one segment intervenes, and when two segments intervene, the reduction is expected to be roughly $4.3 \mathrm{~ms}$ ( \pm $0.722 \mathrm{~ms}$ ). Note that while the effect is somewhat smaller than the cumulative estimated effects in Table 12, it is nonetheless well within the range demarcated by the cumulative standard errors of the effects. Hence, 
Table 13: Fixed effects of model predicting duration and including distance from a preceding /a/ in sonoritydriven stress experiment.

\begin{tabular}{|c|c|c|c|}
\hline & Estimate & Std. Error & $\mathrm{t}$ value \\
\hline (Intercept) & 136.920 & 3.254 & 42.08 \\
\hline /ə/ & -72.564 & 2.034 & -35.68 \\
\hline /e/ & -44.637 & 1.943 & -22.98 \\
\hline /i/ & -42.626 & 2.021 & -21.09 \\
\hline$/ \mathrm{O} /$ & -12.944 & 2.035 & -6.36 \\
\hline$/ \mathrm{u} /$ & -33.427 & 1.923 & -17.38 \\
\hline$\frac{\text { prior a }}{\# \text { of intervening C }}$ & -8.567 & 1.444 & -5.93 \\
\hline
\end{tabular}

the model in Table 13 captures the desired effect more parsimoniously. At this juncture, the evidence does not weigh in favor of the proposal that Gujarati has sonority-driven stress.

\subsubsection{FO and intensity}

While duration and F1/F2 show fairly substantial effects that are plausibly the result of coarticulation, F0 and intensity have very small effects that are nonetheless resistant to alternative explanations. If stress follows the predictions of the sonority-driven stress analysis, an extreme value (either high or low) in the F0 contour could be expected to align with the stressed syllable, though given de Lacy's (2002: 71) description, a more modest deviation from the general rising pattern at the stressed syllable is also possible. Regarding intensity, stressed syllables may be expected to have greater intensity than unstressed syllables.

Models were constructed to assess the effect of claimed stress on F0 minimum, maximum, mean and range. In all models of F0 values, F1 was included to control for intrinsic F0 (Peterson \& Barney 1952). Whether a syllable was in an initial or medial syllable was included to control for the general rising intonational pattern.

Additionally, F0 minima overwhelmingly occur at the beginning of the syllable in the data. In order to control for micro-prosody from preceding consonants or F0 depression from a coarticulatory vowel lowering, the model of F0 minimum includes whether the vowel was preceded by a voiced obstruent and whether the preceding vowel was low.

An interaction between stress and gender improves model fit over the baseline for F0 maximum ( $p=$ 0.026, $\Delta \mathrm{AIC}=3.334), \mathrm{F} 0$ minimum $(p=0.023, \Delta \mathrm{AIC}=3.585)$ and $\mathrm{F} 0$ mean $(p=0.019, \Delta \mathrm{AIC}=3.976)$ and $\mathrm{F} 0$ range $(p=0.11, \Delta \mathrm{AIC}=0.43)$. In the models of $\mathrm{F} 0$ minimum, maximum and mean, unstressed vowels had lower values by $1.6-2.3 \mathrm{~Hz}$ for females and $0.3-1.1 \mathrm{~Hz}$ for males. The stress effects were uniformly not robust, with absolute t-values all less than 1.85. Note that while the statistical models detect a weak effect, it is very unlikely that a human listener would detect these differences, as the reported just-noticeable difference for F0 in running speech is between 5 and $16 \mathrm{~Hz}$ (Harris \& Umeda 1987). ${ }^{12}$

For intensity, both the baseline and the stress models include fixed effects for mean F0, F1 and duration on intensity. Again, model fit is significantly improved $(p<0.01, \Delta \mathrm{AIC}=3.775)$ relative to the baseline model. However, unstressed vowels have a very small $(0.46 \mathrm{~dB})$ reduction in vowel intensity $(t=-2.742)$. Just noticeable differences for overall intensity are somewhat difficult to report, as intensity JNDs vary by frequency (Florentine et al. 1987), but the observed effect in the data is smaller than the tentative JND of 1.2-1.5 dB reported by Flanagan (1955) for synthesized /ə/ with F0 of $120 \mathrm{~Hz}$.

\footnotetext{
${ }^{12}$ The effect persists even when the same models described here are fitted to the full set of items used in all experiments. However, the size of the effect on F0 for female speakers still stays below $4 \mathrm{~Hz}$.
} 


\subsection{Local summary}

Where experiment 1 showed F0, coarticulation in F1/F2 and potentially duration to be affected by an asymmetry between initial and non-initial syllables, experiment 2 fails to show strong effects associated with the sonority-driven stress analysis. The more robust effects in duration and F1/F2 are plausibly explained by an account that does not appeal to stress. Meanwhile, F0 and intensity show statistically significant correlations with sonority-driven stress, although the effect sizes are not ecologically significant. In all, the available acoustic correlates of stress under either theory point to stress being phonetically weak at best. The next section examines speakers' intuitions on stress.

\section{Experiment 3: stress intuitions}

Speakers of stress languages often have intuitions about which syllable is the most prominent in a word. In this experiment participants were asked which syllable of trisyllabic words was the most prominent.

\subsection{Method and materials}

The same participants from the previous two experiments participated in this task. Participants were taught how to tap their fingers simultaneously with the production of a prominent syllable. The author modeled the procedure using multi-syllabic English words, and a native speaker assistant modeled the procedure using Gujarati words. Participants would often spontaneously repeat the syllable they thought was stressed after simultaneously tapping during the pronunciation of the word. The full set of 26 words used in experiments 1 and 2 was randomized after the collection of acoustic data, and revealed sequentially to participants.

Some speakers gave non-standard spelling pronunciations for some items in the set, in particular [səy.kul.ta] 'complexity' and [bor.sə.li] 'tree species' were prone to being pronounced [səy.ku.lə.ta] and [bo.rəs.li]. ${ }^{13}$ Since these pronunciations indicate a lack of familiarity with the word, stress judgements (and acoustic measurements reported above) were excluded when these pronunciations were given. Furthermore, [səy.kul.ta] was sometimes pronounced correctly, but stress would be reported to fall on $/ 1 /$, rather than on an entire syllable [kul]. Such responses will also not be considered in the results below.

\subsection{Stress intuition results}

Participants did not have consistent intuitions on the location of prominence. No word had a consensus syllable that all participants agreed was stressed, and for only six words was there agreement between roughly two thirds of participants. Perhaps more importantly, the stress position as predicted by either the initial stress analysis or de Lacy $(2002 ; 2006)$ does not generally coincide with the majority or plurality pick. This can be seen in Table 14, where the most frequently selected syllable is bolded, and the syllable predicted to be stressed by de Lacy's analysis is underlined.

It is immediately apparent from Table 14 that the participants did not converge on the location of stress. Any categorical model of stress is necessarily going to make substantial errors in describing these data. Nonetheless, the existing theories of Gujarati stress poorly predict the responses of speakers. Under de Lacy's analysis, the predicted stressed syllable only coincides with the most frequently selected syllable for 12 out of 26 words. Furthermore, de Lacy's analysis often misses by large margins, with an average disparity of 22 percentage points between the predicted stressed syllable and the most commonly selected syllable.

Fixed-stress analyses do not perform well either, as a plurality of participants indicated that the first, second or third syllables were prominent for roughly equal numbers of words. Specifically, a plurality of speakers selected the first syllable for 11 words, while the second syllable was selected by a plurality for 9 words and the third syllable was selected by a plurality for 10 words (counts do not sum to 26 due to ties). The

\footnotetext{
${ }^{13}$ Gujarati orthography usually does not represent ///, so for unknown words, speakers must guess whether an orthographic cluster is broken up by a schwa, and in longer orthographic clusters, they must also guess the location of the schwa.
} 
Table 14: Rates of syllable selection in the tap test.

\begin{tabular}{|c|c|c|c|c|c|}
\hline \multirow[b]{2}{*}{ no. } & \multirow[b]{2}{*}{ Word } & \multicolumn{3}{|c|}{ Percent $\sigma$ Selected } & \multirow[b]{2}{*}{ Gloss } \\
\hline & & 1 & 2 & 3 & \\
\hline 1 & man.ha.ni & 27 & $\underline{27}$ & 45 & 'insult' \\
\hline 2 & sə.man.ta & 0 & $\underline{65}$ & 35 & ‘similarity’ \\
\hline 3 & hə.nu.man & 4 & $\overline{57}$ & $\underline{39}$ & 'name of deity' \\
\hline 4 & bor.sə.li & $\underline{33}$ & 33 & $\overline{33}$ & 'tree species' \\
\hline 5 & tฮə.ni.bor & 8 & $\underline{62}$ & 29 & 'type of berry' \\
\hline 6 & hit.va.di & 45 & $\underline{23}$ & 32 & 'advisor' \\
\hline 7 & ma.hit.gar & $\underline{0}$ & 64 & 36 & 'informer' \\
\hline 8 & pu.ro.hit & 17 & $\underline{17}$ & 67 & 'family priest' \\
\hline 9 & kul.pə.ti & $\underline{50}$ & 5 & 45 & 'high ranking official' \\
\hline 10 & səy.kul.ta & $\overline{60}$ & 40 & $\underline{0}$ & 'complexity' \\
\hline 11 & gu.ru.kul & 13 & $\underline{13}$ & 74 & 'religious school' \\
\hline 12 & na.rəy.gi & $\underline{0}$ & 79 & 21 & 'orange' \\
\hline 13 & na.rad్.gi & 9 & $\underline{32}$ & 59 & 'distressed' \\
\hline 14 & da.bo.di & $\underline{26}$ & 35 & 39 & 'lefty’ \\
\hline 15 & әm.bo.d.o & 71 & $\underline{17}$ & 12 & 'hair bun' \\
\hline 16 & sam.be.lo & $\underline{59}$ & $\overline{27}$ & 14 & 'rod' \\
\hline 17 & tə.be.lo & 29 & $\underline{43}$ & 29 & 'horse stable' \\
\hline 18 & dुzam.bu.do & $\underline{65}$ & 26 & 9 & 'jambul tree' \\
\hline 19 & lim.bu.di & $\overline{67}$ & 8 & 25 & 'lemon tree' \\
\hline 20 & da.gi.no & $\underline{23}$ & 59 & 18 & ‘jewelry’ \\
\hline 21 & nə.gi.no & 0 & $\underline{50}$ & 50 & ‘jewel’ \\
\hline 22 & su.mə.ti & $\underline{45}$ & 9 & 45 & ‘wisdom’ \\
\hline 23 & səm.mə.ti & $\overline{57}$ & $\underline{8}$ & 17 & 'consensus' \\
\hline 24 & kə.vi.ta & 22 & 35 & 43 & 'poem’ \\
\hline 25 & pə.rik. $\int a$ & 4 & 35 & $\underline{61}$ & 'test' \\
\hline 26 & hõ.ji.jar & 46 & 38 & $\underline{17}$ & 'intelligent' \\
\hline
\end{tabular}


fixed stress analyses also have large average disparities from the most commonly selected syllable. If stress is assumed to be initial, the average disparity between the predicted stressed syllable and the most commonly selected syllable is 26 percentage points, while a penultimate stress analysis has an average disparity of 21 percentage points and a final stress analysis has a 23 percentage point average disparity.

Going beyond the prior theories of stress, a superior, but by no means flawless, account of these data states that the leftmost closed syllable is stressed, and if no syllables are closed, then the penultimate syllable is stressed. Such an analysis correctly predicts the most frequently selected syllable 17 times out of these 26 words, and has an average disparity from the most frequently selected syllable of 8 percentage points. Further adjustments can modestly increase the accuracy of this analysis, for instance, by analyzing the first syllable of [hõ.fi.jar] 'intelligent' as heavy and stressed due to a latent nasal coda. Another option is to ban stress from open schwa, so that either the initial or final syllable in [su.mə.ti] 'wisdom' may be stressed. ${ }^{14}$ With these improvements, the analysis only misses the most frequently selected syllable by an average of 5 percentage points. Nonetheless, there are still significant errors, as the most frequently selected syllable in seven words is missed.

Given these errors, and the variability in the responses, this alternative is unlikely to be the correct model of Gujarati stress. The chief conclusion from the examination of speaker intuitions is that Gujarati speakers appear to not have strong intuitions on the relative prominence of syllables within a word.

\section{Conclusion}

The experiments reported here found modest acoustic evidence in favor of fixed initial stress, failed to find clear acoustic correlates of sonority-driven stress as described by de Lacy $(2002 ; 2006)$, and found that speakers have inconsistent stress intuitions. These results are in keeping with other recent literature on Gujarati (Shih 2016; 2018).

On balance, the evidence favors the initial stress analysis of Gujarati. Not only are pitch contours sensitive to initial syllables and more contrasts found in initial syllables, but this study also found greater duration and resistance to coarticulation in initial syllables. Though further investigation is warranted on the latter correlates of stress, the first two by themselves have been used as sufficient support for initial stress analyses of nearby languages in Keane $(2006 ; 2014)$ and Khan $(2008 ; 2014)$. As an aside, the default rising contour observed in this study provides further evidence of a South Asian intonational sprachbund with phonetically weak stress (Féry 2010; Khan 2016).

However, it may be premature to discard sonority-driven analyses of Gujarati stress entirely. Only de Lacy's $(2002 ; 2006)$ proposal was tested here, and numerous alternatives exist in the literature. Even if de Lacy's analysis is ultimately rejected, it is possible that one of the alternatives could still be correct. Furthermore, some acoustic parameters did correlate with stress as described by de Lacy, and no alternative explanation is readily available. While the effects reported here are almost certainly too small for learners to leverage while acquiring stress, it would be inappropriate to dismiss the correlations as spurious at this time. It is possible that the observed effects are by-products of some different parameter with sufficient magnitude to cue stress, like spectral tilt or consonant glottalization, that has not been examined here, since this study focused on the cues that had been mentioned in the prior literature on Gujarati.

Ultimately, this study highlights the importance of providing corroborating evidence for stress analyses. The acoustic correlates of stress vary between languages, as has been known for some time (see Hayes 1995 for a general overview, see also Sluijter \& van Heuven 1997; Gordon \& Nafi 2012 for noteworthy specific studies) and cues that lead an investigator to propose stress in one language may be valid in the investigator's native language but not in the language under study, a phenomenon dubbed stress ghosting by Tabain et al. (2014, see also Bowern et al. 2013). In light of the possibility of stress ghosting, it is imperative that analyses

\footnotetext{
${ }^{14}$ In the case of [suməti] 'wisdom', speakers selected each syllable equally, so it is not possible to state what the prefered direction of stress shift is.
} 
of abstract properties like stress be closely informed by empirical facts, whether they be systematically collected native speaker prominence judgements, phonological dependencies, or phonetic measures. The need for strong empirical verification is especially urgent in a case like Gujarati, where the sonority-driven analysis is both typologically unusual and has played a large role in theoretical developments like scalar markedness theory. (Tabain et al., 2014)

\section{References}

Adenwala, Mridula. 1965. The structural analysis of phonology and morphemics of Gujarati: State University of New York at Buffalo dissertation.

Arnold, Todd W. 2010. Uninformative parameters and model selection using Akaike's Information Criterion. Journal of Wildlife Management 74. 1175-1178.

Bates, Douglas, Martin Mächler, Ben Bolker \& Steve Walker. 2015. Fitting linear mixed-effects models using lme4. Journal of Statistical Software 67(1). https://doi.org/10.18637/jss.v067.i01.

Beckman, Jill. 1998. Positional faithfulness: University of Massachusetts dissertation.

Beckman, Mary. 1986. Stress and non-stress accent. Dordrecht: Foris.

Beckman, Mary \& Janet Pierrehumbert. 1986. Intonational structure in Japanese and English. Phonology Yearbook 3. 255-309.

Bowern, Claire, Barry Alpher \& Erich Round. 2013. Yidiny stress, length and truncation revisited. Handout of poster presented at NELS 44. https://pamanyungan.sites.yale.edu/yidiny.

Burnham, Kenneth P. \& David R. Anderson. 2002. Model selection and multimodel inference: A practical information-theoretic approach. New York: Springer-Verlag.

Cardona, George. 1965. A Gujarati reference grammar. University of Pennsylvania.

Cardona, George \& Babu Suthar. 2003. Gujarati. In George Cardona \& Dhanesh Jain (eds.), The Indo-Aryan languages, 660-697. Routledge.

Cho, Taehong. 2004. Prosodically conditioned strengthening and vowel-to-vowel coarticulation in English. Journal of Phonetics 32. 141-176.

Cho, Taehong \& Patricia Keating. 2001. Articulatory and acoustic studies on domain-initial strengthening in Korean. Journal of Phonetics 29. 155-190.

Cho, Taehong \& Patricia Keating. 2009. Effects of initial position versus prominence in English. Journal of Phonetics 37. 466-485.

Crowhurst, Megan \& Lev D. Michael. 2005. Iterative footing and prominence-driven stress in Nanti (Kampa). Language 81(1). 47-95.

Desai, Urmi. 1992. Vyakarana vimarśa [a grammatical treatise]. Ahmedabad: University Grantha Nirmana Board dissertation.

Doctor, Raimond. 2004. A grammar of Gujarati. Munich: Lincom Europa.

Féry, Caroline. 2010. Indian languages as intonational 'phrase' languages. In Imtiaz Hasnain \& Shreesh Chaudhury (eds.), Problematizing language studies; cultural, theoretical and applied perspectives: Essays in honor of Rama Kant Agnihotri, 288-312. Delhi: Aakar Books.

Firth, John Rupert. 1957. Phonetic observations on Gujarati. Bulletin of the School of Oriental and African Studies 20. 231-241.

Flanagan, James L. 1955. Difference limen for the intensity of a vowel sound. Journal of the Acoustic Society of America 27. 1223-1225.

Florentine, Mary, Soren Buus \& Christine Mason. 1987. Level discrimination as a function of level for tone from 0.25 to $16 \mathrm{khz}$. Journal of the Acoustic Society of America 81. 1528-1541.

Fougeron, Cécile \& Patricia Keating. 1997. Articulatory strengthening at edges of prosodic domains. Journal of the Acoustical Society of America 101. 3728-3740.

Fowler, Carol A. 1981. A relationship between coarticulation and compensatory shortening. Phonetica 38. 
$35-50$.

Gordon, Matthew \& Latifa Nafi. 2012. Acoustic correlates of stress and pitch accent in Tashlhiyt Berber. Journal of Phonetics 40. 706-724.

Hargus, Sharon. 2001. Quality-sensitive stress reconsidered. In Susannah Levi (ed.), University of Washington working papers in linguistics, vol. 20, 25-56. University of Washington.

Harris, M. S. \& N. Umeda. 1987. Difference limen for fundamental frequency contours in sentences. Journal of the Acoustical Society of America 81. 1139-1145.

Hayes, Bruce. 1995. Metrical stress theory. Chicago: The University of Chicago Press.

Hirano, Mirano, John Ohala \& William Vennard. 1969. The function of laryngeal muscles in regulating fundamental frequency and intensity of phonation. Journal of Speech Language and Hearing Research 12(3). 616.

Keane, Elinor. 2006. Prominence in Tamil. Journal of the International Phonetic Association 36(1). 1-20.

Keane, Elinor. 2014. Tamil. In Sun-Ah Jun (ed.), Prosodic typology II: The phonology of intonation and phrasing, 118-153. Oxford: Oxford University Press.

Keating, Patricia, Taehong Cho, Cécile Fougeron \& Chai-Shune Hsu. 2003. Domain-initial strengthening in four languages. In John Local, Richard Ogden \& Rosalind Temple (eds.), Papers in laboratory phonology vi, 145-163. Cambridge: Cambridge University Press.

Kenstowicz, Michael. 1997. Quality-sensitive stress. Rivista de Linguistica 9(1). 157-187.

Khan, Sameer. 2008. Intonational phonology and focus prosody of Bengali: University of California, Los Angeles dissertation.

Khan, Sameer. 2014. The intonational phonology of Bangladeshi Standard Bengali. In Prosodic typology ii: The phonology of intonation and phrasing, Oxford University Press.

Khan, Sameer ud Dowla. 2016. The intonation of South Asian languages: Towards a comparative analysis. In Proceedings of formal approaches to South Asian languages, vol. 6, 23-36.

de Lacy, Paul. 2002. The formal expression of markedness: University of Massachusetts, Amherst dissertation.

de Lacy, Paul. 2006. Markedness: Reduction and preservation in phonology Cambridge Studies in Linguistics. Cambridge University Press.

Lieberman, Phil. 1960. Some acoustic correlates of word stress in American English. Journal of the Acoustical Society of America 32. 451-454.

Magen, H. S. 1997. The extent of vowel-to-vowel coarticulation in English. Journal of Phonetics 25. 187205.

Master, Alfred. 1925. Stress accent in modern Gujarātī. Journal of the Bombay Branch of the Royal Asiatic Society 1. 76-94.

Mistry, P. J. 1997. Gujarati. In Alan S. Kaye (ed.), Phonologies of Asia and Africa, vol. 2, 653-673. Pennsylvania: Eisenbrauns.

Modi, Bharati. 1994. The phonetics and phonology of mid-vowels in Gujarati. Indian Linguistics 55. 51-76. Modi, Bharati. 2013. Some issues in Gujarati phonology. Munich: Lincom Europa.

Moore, Brian. 1995. An introduction to the psychology of hearing. San Diego: Academic Press.

Nair, Usha. 1979. Gujarati phonetic reader. Mysore: Central Institute of Indian Languages.

Pandit, Prabodh. 1958. Duration, syllable and juncture in Gujarati. Indian Linguistics: Turner Jubilee 1. 212-218.

Patel, M. S. \& J. J. Mody. 1960. The vowel system of Gujarati. Maharaja Sayajirao University of Baroda.

Peterson, Gordon E. \& Harold L. Barney. 1952. Control methods used in a study of the vowels. The Journal of the Acoustical Society of America 24. 175-184.

Pierrehumbert, Janet. 1980. The phonology and phonetics of English intonation: MIT dissertation.

$\mathrm{R}$ Core Team. 2018. $R$ : A language and environment for statistical computing. R Foundation for Statistical Computing Vienna, Austria. https://www.R-project.org/. 
Recasens, Daniel. 2012. A study of jaw coarticulatory resistance and aggressiveness for Catalan consonants and vowels. Journal of the Acoustical Society of America 132(1). 412-420.

Recasens, Daniel. 2015. The effect of stress and speech rate on vowel coarticulation in Catalan vowelconsonant-vowel sequences. Journal of Speech, Language and Hearing Research 58. 1407-1424.

Recasens, Daniel \& Aina Espinosa. 2009. An articulatory investigation of lingual coarticulator resistance and aggressiveness for consonants and vowels in Catalan. Journal of the Acoustical Society of America 125(4). 2288-2298.

Schiering, René \& Harry van der Hulst. 2010. Accentual systems in the languages of Asia. In Harry van der Hulst, Rob Goedemans \& Ellen van Zanten (eds.), Stress patterns of the world: Part II, 509-614. Mouton de Gruyter.

Shih, Shu-hao. 2016. Sonority-driven stress does not exist. In Supplemental proceedings of the 2015 meeting on phonology, .

Shih, Shu-hao. 2018. On the existence of sonority-driven stress: Gujarati. Phonology 35(2). 327-364.

Sluijter, Agaath M. C. \& Vincent van Heuven. 1997. Spectral balance as an acoustic correlate of linguistic stress. Journal of the Acoustical Society of America 100(4). 2471-2485.

Tabain, Marija, Janet Fletcher \& Andrew Butcher. 2014. Lexical stress in Pitjantjatjara. Journal of Phonetics 42. 52-66.

Titze, Ingo. 1988. Regulation of vocal power and efficiency by subglottal pressure and glottal width. In Osamu Fujimura (ed.), Vocal physiology: Voice production, mechanisms and functions, 227-239.

Titze, Ingo. 2000. Principles of voice production. Salt Lake City: National Center for Voice and Speech.

Turner, R. L. 1921. Gujarati phonology. The Journal of the Royal Asiatic Society of Great Britain and Ireland 3. 329-365.

Yun, Gwanhi. 2007. Word frequency, stress and coarticulation in English. Studies in Phonetics, Phonology and Morphology 13. 315-331.

Dustin Bowers

Department of Linguistics

P.O. Box 210025

The University of Arizona

Tucson AZ 85721USA

bowersd@email.arizona.edu 